Supplementary Information for:

\title{
Photodegradation of fludioxonil and other pyrroles: The importance of indirect photodegradation for understanding environmental fate and photoproduct formation
}

Jennifer N. Apell, Nicholas C. Pflug, and Kristopher McNeill*

Institute for Biogeochemistry and Pollutant Dynamics, ETH Zurich, Universitaetstrasse 16, 8092 Zurich, Switzerland.

*kris.mcneill@env.ethz.ch

\section{Lamp Irradiance Spectra}

Figure S1. Irradiance spectra for UVB, UVA, and xenon lamps ...................................... 3

\section{Molar Absorptivity}

Table S1. Values for the gaussian curves that reconstruct the molar absorptivity curve ........... 4

Discussion: Molar absorptivity spectrum for fludioxonil and other pyrroles ........................ 4

Figure S2. Molar absorptivity $\left(\varepsilon_{\lambda}\right)$ of fludioxonil and other pyrroles ................................ 5

\section{Direct Photodegradation Kinetics}

Figure S3. Degradation kinetics of fludioxonil exposed to UVB lamps .............................. 6

Figure S4. Degradation kinetics of fludioxonil exposed to a xenon lamp ............................ 6

Figure S5. Relative rate of photon absorption of fludioxonil........................................ 7

Degradation of Fludioxonil Under Various Experimental Conditions

Figure S6. Degradation of fludioxonil with $\bullet \mathrm{OH}$ against the probe benzoate.......................... 7

Figure S7. Degradation kinetics of fludioxonil with varying $\left[\mathrm{NaN}_{3}\right]$ as a quencher................ 8

Figure S8. Quenching of the fludioxonil reaction with ${ }^{1} \mathrm{O}_{2}$ by $0.3-3 \mathrm{mM}$ of $\mathrm{N}_{3}{ }^{-} \ldots \ldots \ldots \ldots \ldots \ldots \ldots$

Figure S9. Comparison of degradation kinetics of fludioxonil using PN sensitizer or ZnP

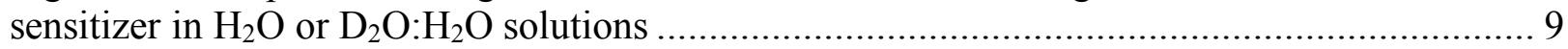

Figure S10. Degradation kinetics of fludioxonil and 3-cyanopyrrole with model sensitizers .... 10

NMR and Mass Spectra of Fludioxonil and Photoproducts

Table S2. ${ }^{1} \mathrm{H}$ NMR assignments of fludioxonil and products ............................................. 11

Table S3. ${ }^{13} \mathrm{C}$ NMR assignments of fludioxonil and products ......................................... 11

Table S4. HMBC correlations for fludioxonil and products ......................................... 11

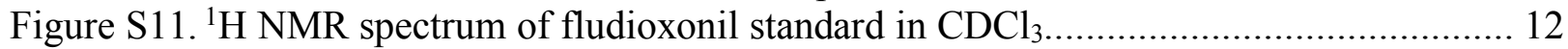

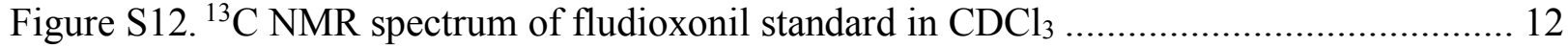

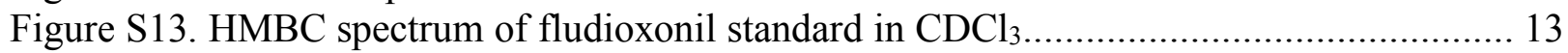

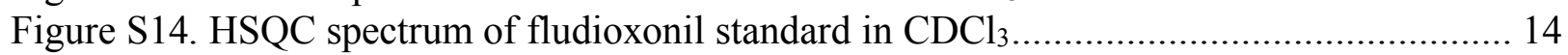

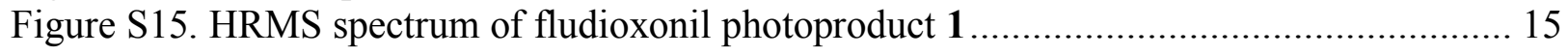


Figure S16. HRMS spectrum of fludioxonil photoproduct 2 ................................................. 15

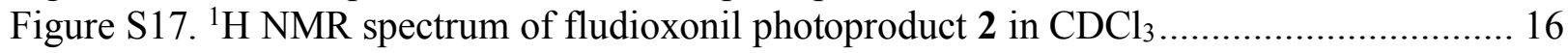

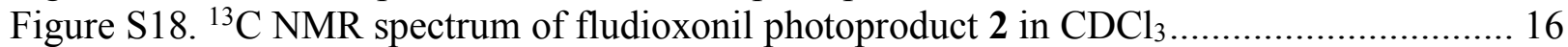

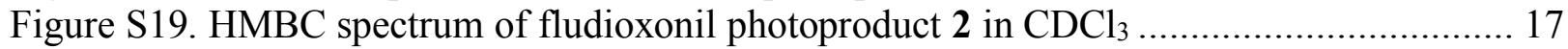

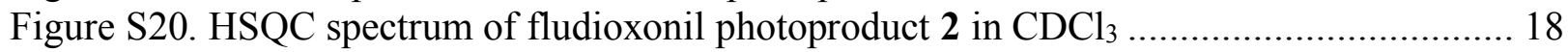

Figure S21. HRMS spectrum of fludioxonil photoproduct 3 ……………............................ 19

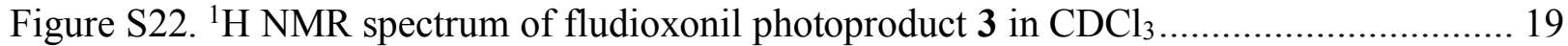

Figure S23. HRMS spectrum of fludioxonil photoproduct 4 …........................................... 20

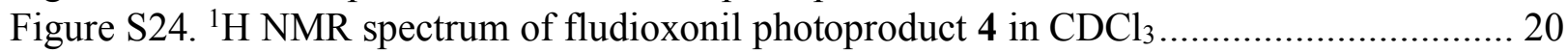

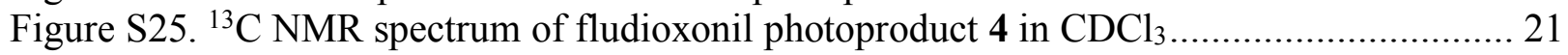

Figure S26. HMBC spectrum of fludioxonil photoproduct 4 in $\mathrm{CDCl}_{3}$................................ 22

Figure S27. HSQC spectrum of fludioxonil photoproduct 4 in $\mathrm{CDCl}_{3}$................................. 23

\section{Photoproduct Formation}

Figure S28. Degradation of fludioxonil and formation of product $\mathbf{2}$ in xenon and UVA light with

$1 \mu \mathrm{M}$ PN

Figure S29. Structure of potential fludioxonil photoproducts................................................... 24

Figure S30. Chromatogram of DNPH adduct products at $\lambda=350 \mathrm{~nm} \ldots \ldots \ldots \ldots \ldots \ldots \ldots \ldots \ldots \ldots \ldots \ldots . . .25$

Figure S31. 1H NMR spectrum of fludioxonil photolysis mixture in 50:50 CD3CN:D2O

showing proton signals for photoproducts 1-3 .............................................................. 26

Figure S32. HSQC spectrum of fludioxonil photolysis mixture in 50:50 CD3CN:D2O for photoproducts 1-3 and dimer impurity

Figure S33. Direct photodegradation of fludioxonil and formation of photoproduct 1 in water solutions with no treatment, sparged with Ar, and with the addition of phenol........................ 28 Figure S34. Complete proposed degradation pathway for both direct and indirect

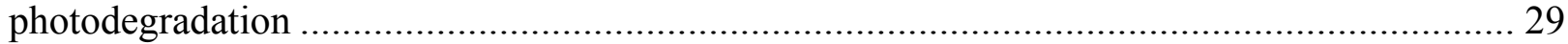

Discussion: Degradation of Photoproduct 1 1.................................................................. 30

\section{Laser Flash Photolysis Experiments}

Figure S35. Laser flash photolysis of 3-phenylpyrrole with direct ionization ........................... 30

Figure S36. Laser flash photolysis of fludioxonil sensitized with 3MAP ................................ 31

\section{Reported Photoproducts}

Figure S37. Structures of reported photoproducts.

\section{NMR Assignments and Degradation Kinetics for Pyrroles}

Table S5. ${ }^{1} \mathrm{H}$ NMR assignments for three pyrrole compounds in $\mathrm{CDCl}_{3}$.................................. 33

Table S6. ${ }^{13} \mathrm{C}$ NMR assignments for three pyrrole compounds in $\mathrm{CDCl}_{3} \ldots \ldots \ldots \ldots \ldots \ldots \ldots \ldots \ldots \ldots . . . . . . . . . . . . . .33$

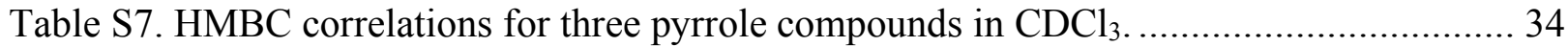

Figure S38. Direct photodegradation of 3-phenylpyrrole .................................................. 34

Figure S39. Comparison of degradation kinetics of pyrroles using PN sensitizer or $\mathrm{ZnP}$ sensitizer

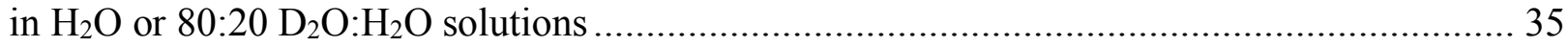

Discussion: Calculating Approximate Reaction Rate Constants with ${ }^{3} \mathrm{PN}^{*}$.............................. 35 


\section{Lamp Irradiance Spectra}

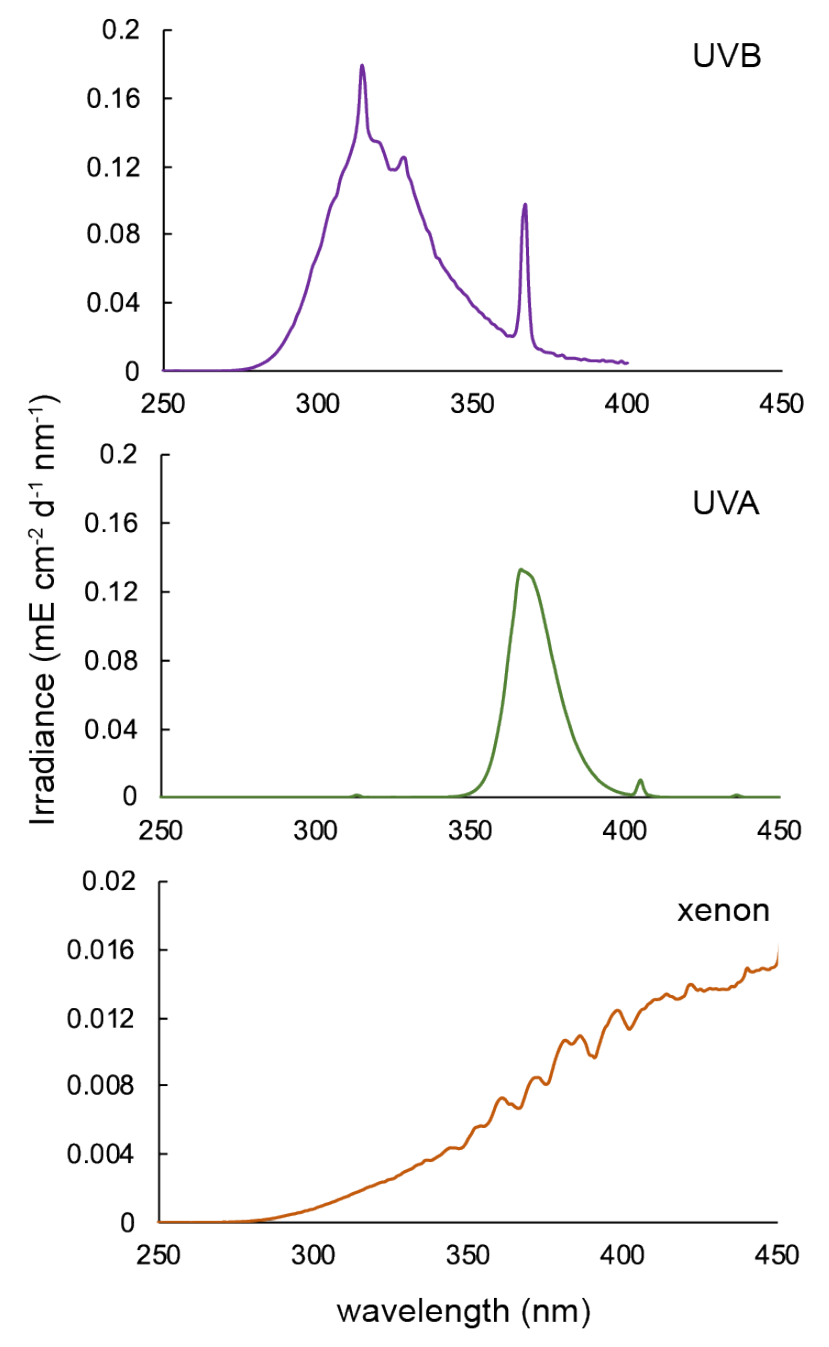

Figure S1. Measured irradiance values for 250 to $450 \mathrm{~nm}$ for (4) UVB bulbs, (4) UVA bulbs, and the xenon lamp from a distance of $70 \mathrm{~cm}$. Relative irradiance values were recorded with an Ocean Optics spectroradiometer, and an actinometer ( $p$-nitroanisole) was used to determine absolute irradiances. 


\section{Molar Absorptivity}

Absorbance data collected on the UV-vis spectrophotometer had a detection limit near $100 \mathrm{M}^{-1}$ $\mathrm{cm}^{-1}$ due to the limited solubility of fludioxonil in water. Therefore, in order to obtain reasonable data at wavelengths that did not exceed the absorbance detection limit (i.e., wavelengths $>305$ $\mathrm{nm}$ ), the data were fit with a series of gaussian curves following equation S1. The reporting of these fitting values in Table $\mathrm{S} 1$ also allow for users to reconstruct the molar absorptivity spectrum.

$$
\varepsilon_{\lambda}=\sum_{i=1}^{n} a_{i} e^{\left[-\left(\frac{\lambda-b_{i}}{c_{i}}\right)^{2}\right]}
$$

Table S1. Values for the series of gaussian curves that reconstruct the molar absorptivity curve $\left(\mathrm{M}^{-1} \mathrm{~cm}^{-1}\right)$ for fludioxonil in water using Equation S1.

\begin{tabular}{|c|c|c|c|c|c|c|c|}
\hline \multicolumn{8}{|c|}{ fludioxonil } \\
\hline coefficient & curve \#1 & curve \#2 & curve \#3 & curve \#4 & curve \#5 & curve \#6 & curve \#7 \\
\hline $\mathbf{a}$ & 5108.3 & 7653.4 & 5800.2 & 41571.8 & 11827.3 & 8567.8 & 2207.3 \\
\hline b & 196.35 & 204.61 & 215.75 & 198.97 & 252.34 & 273.26 & 289.88 \\
\hline c & 4.024 & 8.648 & 6.389 & 22.435 & 20.049 & 14.353 & 7.726 \\
\hline \multicolumn{8}{|c|}{ pyrrole } \\
\hline coefficient & curve \#1 & curve \#2 & curve \#3 & & & & \\
\hline $\mathbf{a}$ & 848.1 & 2091.5 & 4452.2 & & & & \\
\hline b & 217.35 & 208.56 & 197.86 & & & & \\
\hline c & 7.457 & 10.447 & 21.620 & & & & \\
\hline \multicolumn{8}{|c|}{ 3-phenylpyrrole } \\
\hline coefficient & curve \#1 & curve \#2 & curve \#3 & curve \#4 & curve \#5 & curve \#6 & \\
\hline $\mathbf{a}$ & 67716.9 & 3333.1 & 3520.6 & 3659.4 & 1635.9 & 4045.0 & \\
\hline b & 165.47 & 214.42 & 207.75 & 220.59 & 228.06 & 236.09 & \\
\hline c & 22.391 & 5.993 & 7.178 & 6.200 & 6.904 & 12.454 & \\
\hline \multicolumn{8}{|c|}{ 3-cyanopyrrole } \\
\hline coefficient & curve \#1 & curve \#2 & curve \#3 & curve \#4 & curve \#5 & curve \#6 & \\
\hline $\mathbf{a}$ & 1174.4 & 7499.0 & 5965.8 & 5981.1 & 28590.1 & 1069.0 & \\
\hline b & 216.60 & 248.20 & 223.41 & 268.87 & 199.85 & 284.46 & \\
\hline c & 4.751 & 27.243 & 9.809 & 15.616 & 12.081 & 11.019 & \\
\hline
\end{tabular}



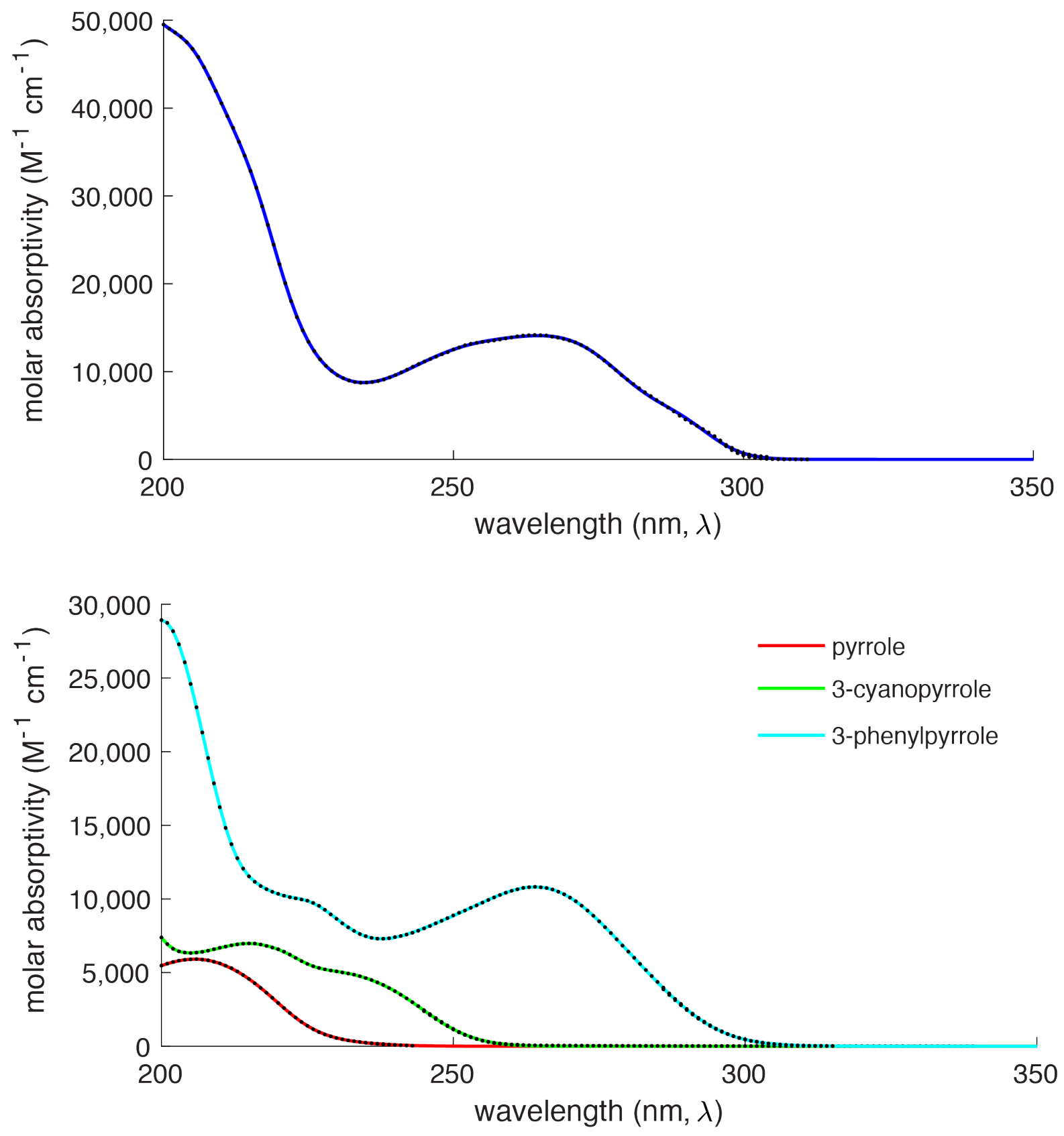

Figure S2. Molar absorptivity ( $\varepsilon$ ) of fludioxonil (top) and pyrrole, 3-cyanopyrrole, and 3phenypyrrole (bottom) in water measured using $1 \mathrm{~cm}$ and $10 \mathrm{~cm}$ pathlength cells in a UV-visible spectrophotometer. The data was fit using a series of gaussian curves in MATLAB (values in Table S1) 


\section{Direct Photodegradation Kinetics}

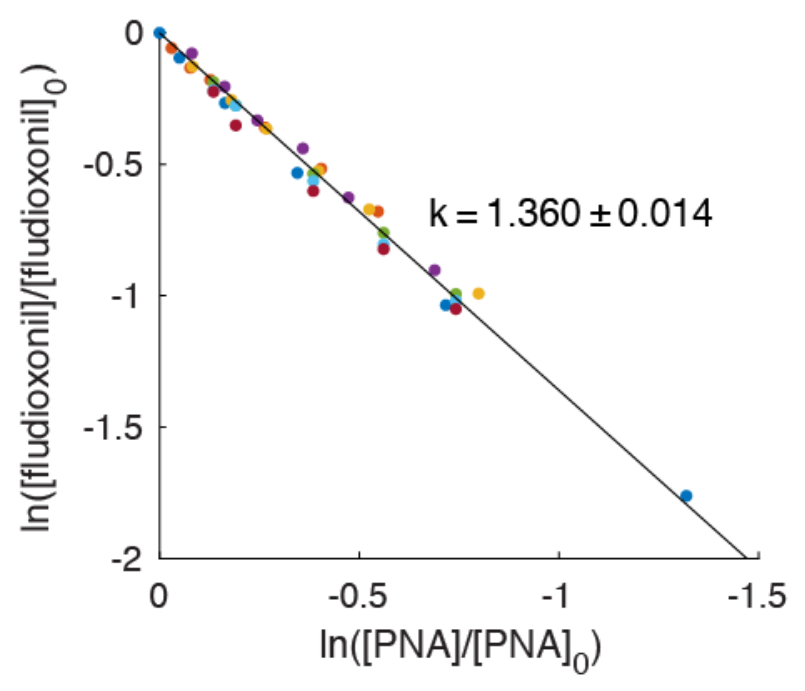

Figure S3. Degradation of fludioxonil against the actinometer p-nitroanisole (PNA) both simultaneously exposed to UVB lamps in 7 replicate experiments. The slope, $\mathrm{k}$, was used to determine to quantum yield of fludioxonil. Each color represents the results from a replicate experiment.

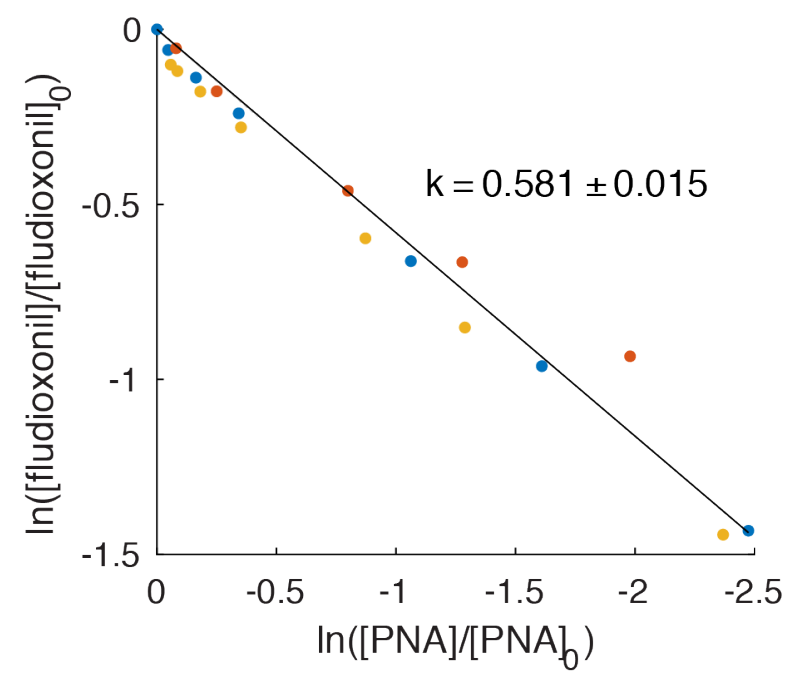

Figure S4. Degradation of fludioxonil against the actinometer p-nitroanisole (PNA) both simultaneously exposed to a xenon lamp in triplicate experiments. The slope, $\mathrm{k}$, was used to determine to quantum yield of fludioxonil. Each color represents the results from a replicate experiment. 


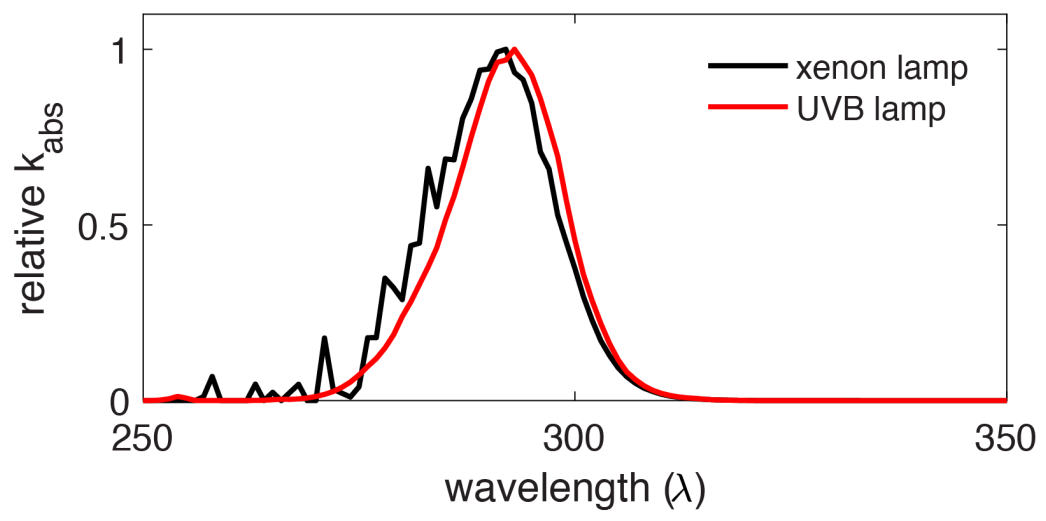

Figure S5. Relative rate of photon absorption of fludioxonil exposed to the UVB lamps and xenon lamps $\left(\mathrm{k}_{\mathrm{abs}}=\Sigma\left(\varepsilon_{\lambda} \mathrm{I}_{\lambda}\right)\right)$.

\section{Degradation of Fludioxonil Under Various Experimental Conditions}

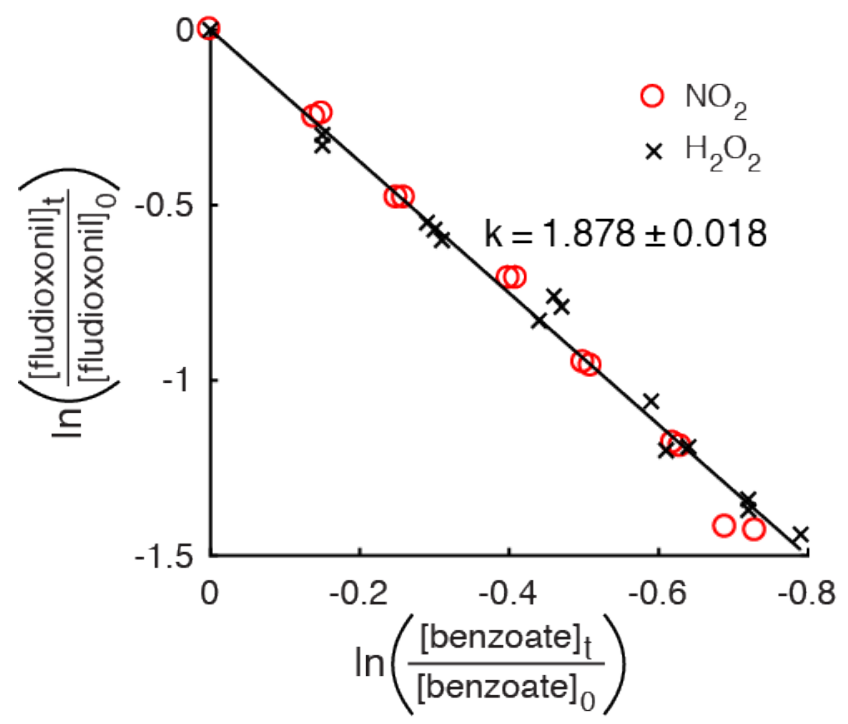

Figure S6. Degradation of fludioxonil against the hydroxyl radical probe benzoate using either $\mathrm{NO}_{2}$ (red circles, duplicate experiments) or $\mathrm{H}_{2} \mathrm{O}_{2}$ (black $\mathrm{x}$, triplicate experiments) as a source for hydroxyl radical when exposed to UVA light in the Rayonet. The bimolecular rate constant was calculated using the competition kinetics approach by multiplying the slope of the graph by the bimolecular rate constant for benzoate and $\bullet \mathrm{OH}\left(5.9 \times 10^{8} \mathrm{M}^{-1} \mathrm{~s}^{-1}\right)$. The statistically indistinguishable slopes using $\mathrm{NO}_{2}$ or $\mathrm{H}_{2} \mathrm{O}_{2}$ as a source of hydroxyl radical indicates that nitrite radical and superoxide are unlikely to react with fludioxonil. 


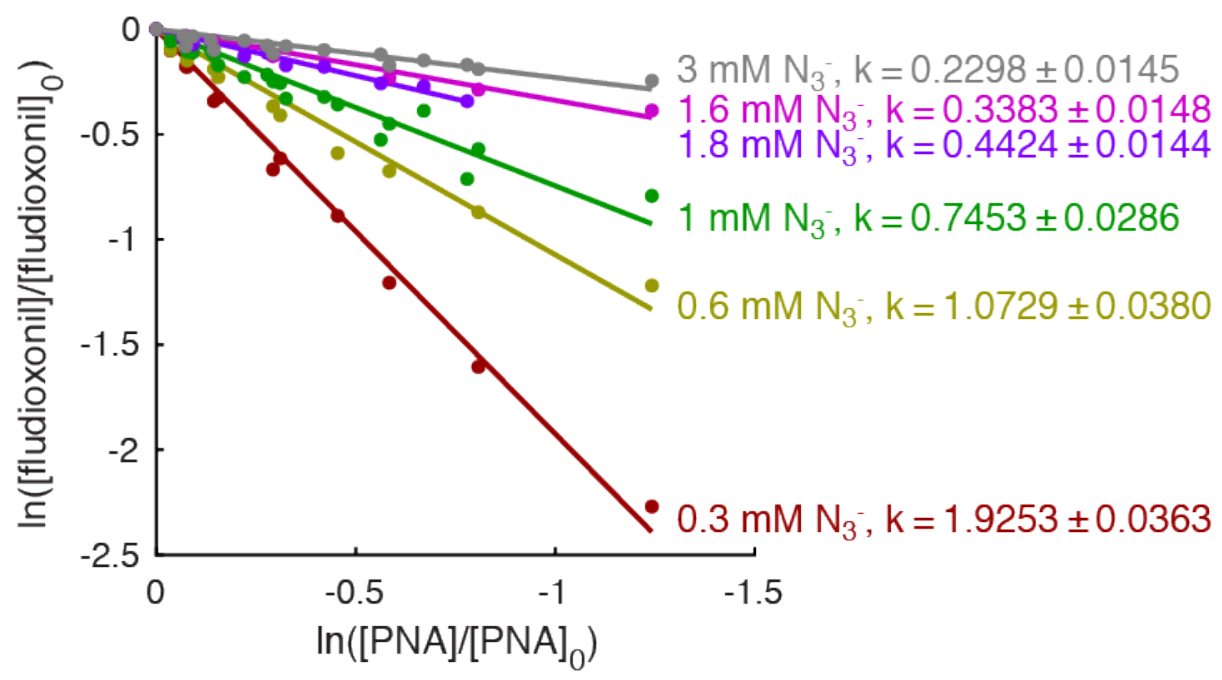

Figure S7. Degradation of fludioxonil against the actinometer p-nitroanisole (PNA) in water containing various amounts of sodium azide $(0.3$ to $3 \mathrm{mM})$. Values for the slopes $(\mathrm{k})$ and the standard error of the slopes are given.

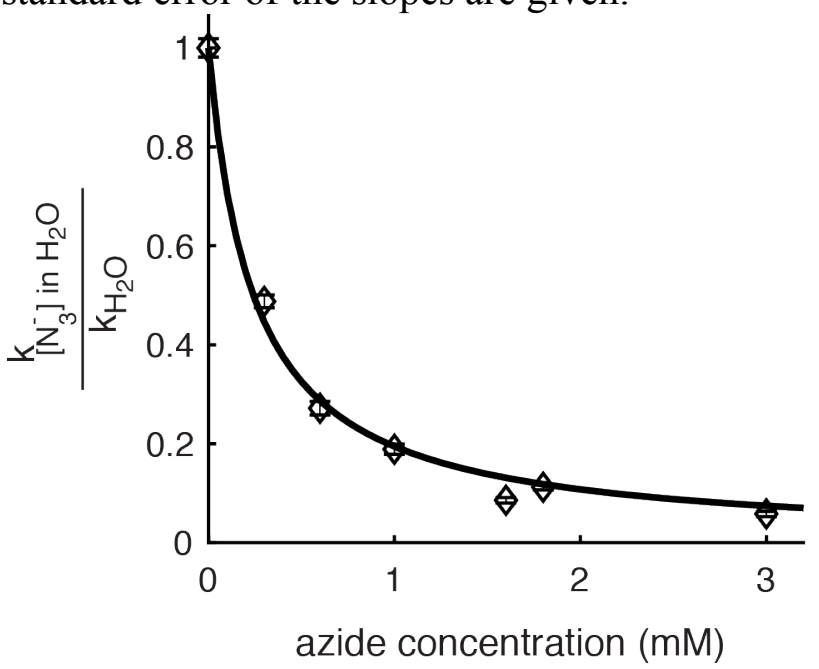

Figure S8. Quenching of the fludioxonil reaction with ${ }^{1} \mathrm{O}_{2}$ by $0.3-3 \mathrm{mM}$ of $\mathrm{N}_{3}{ }^{-}$. Points on the graph are calculated from the degradation kinetics in Figure S7 where the error bars represent the standard error of the slopes. A quenching rate constant of $1.15 \times 10^{9} \mathrm{M}^{-1} \mathrm{~s}^{-1}$ was calculated from the fit. 

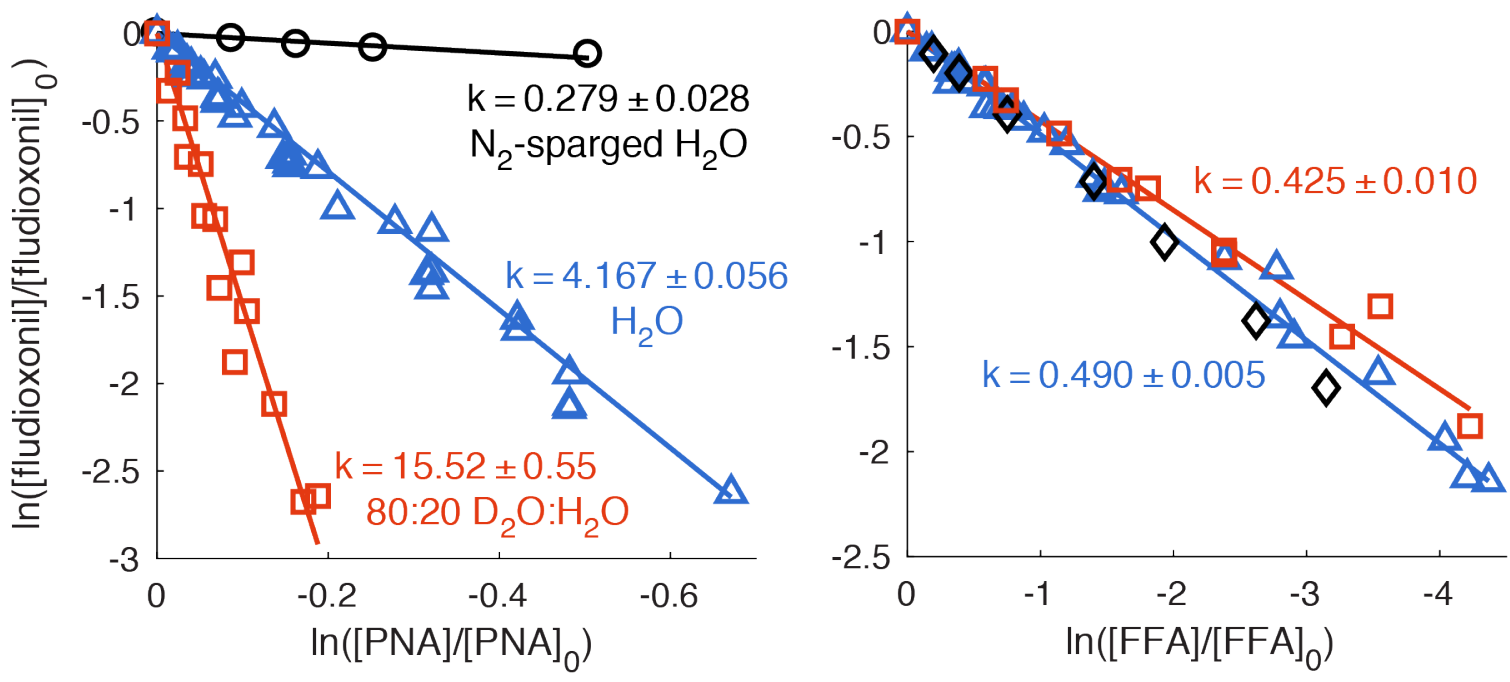

Figure S9. Comparison of degradation in UVA light $(365 \mathrm{~nm})$ of fludioxonil against the actinometer p-nitroanisole (PNA, left panel) and against the singlet oxygen probe furfuryl alcohol (FFA, right panel) in solution containing $1 \mu \mathrm{M}$ of the model sensitizer perinaphthenone (PN) in nitrogen-sparged $\mathrm{H}_{2} \mathrm{O}\left(\mathrm{O}\right.$, single experiment), in $\mathrm{H}_{2} \mathrm{O}(\Delta, 7$ experiments), and in 80:20 $\mathrm{D}_{2} \mathrm{O}: \mathrm{H}_{2} \mathrm{O}(\square$, triplicate experiments). In the right panel, $1 \mu \mathrm{M}$ zinc porphyrin (ZnP) was used as the sensitizer for singlet oxygen $(\diamond$, single experiment). The values of the slopes and their associated standard error are given. 


\section{fludioxonil}
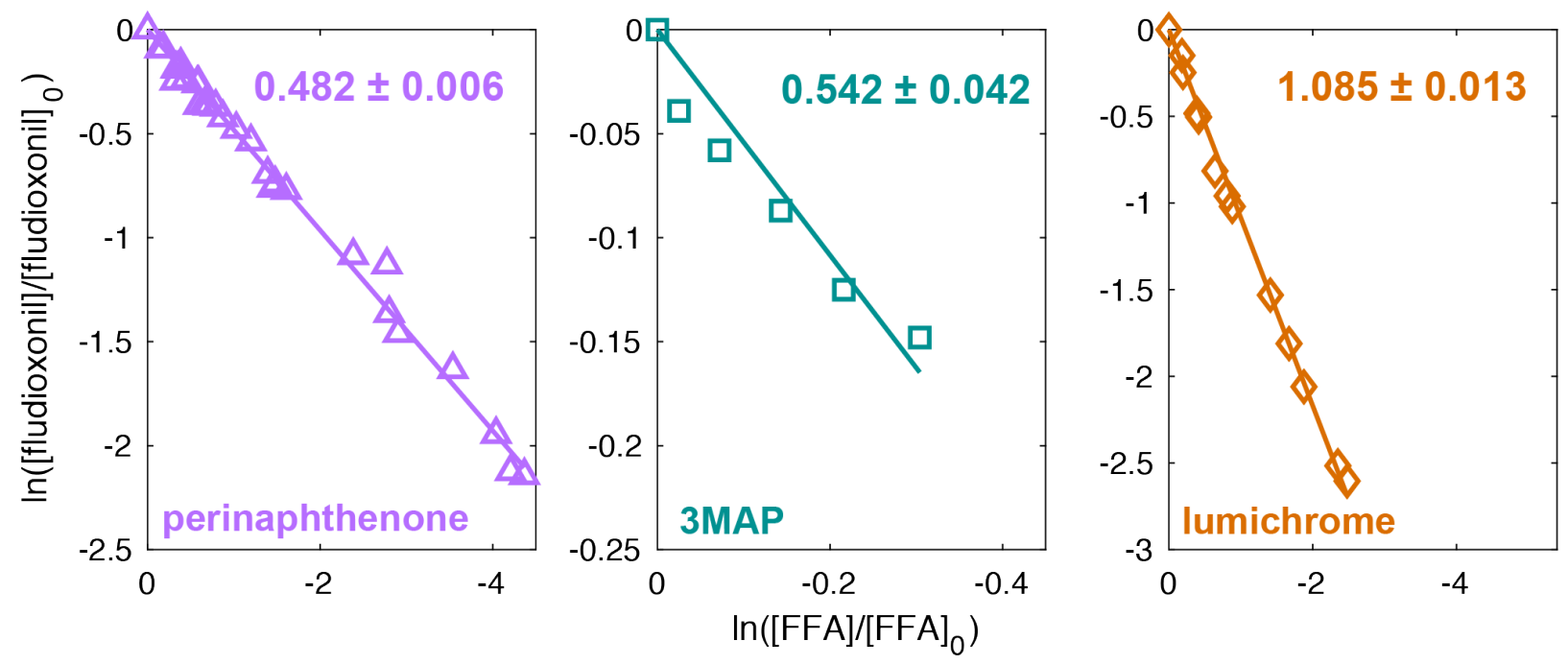

\section{3-cyanopyrrole}
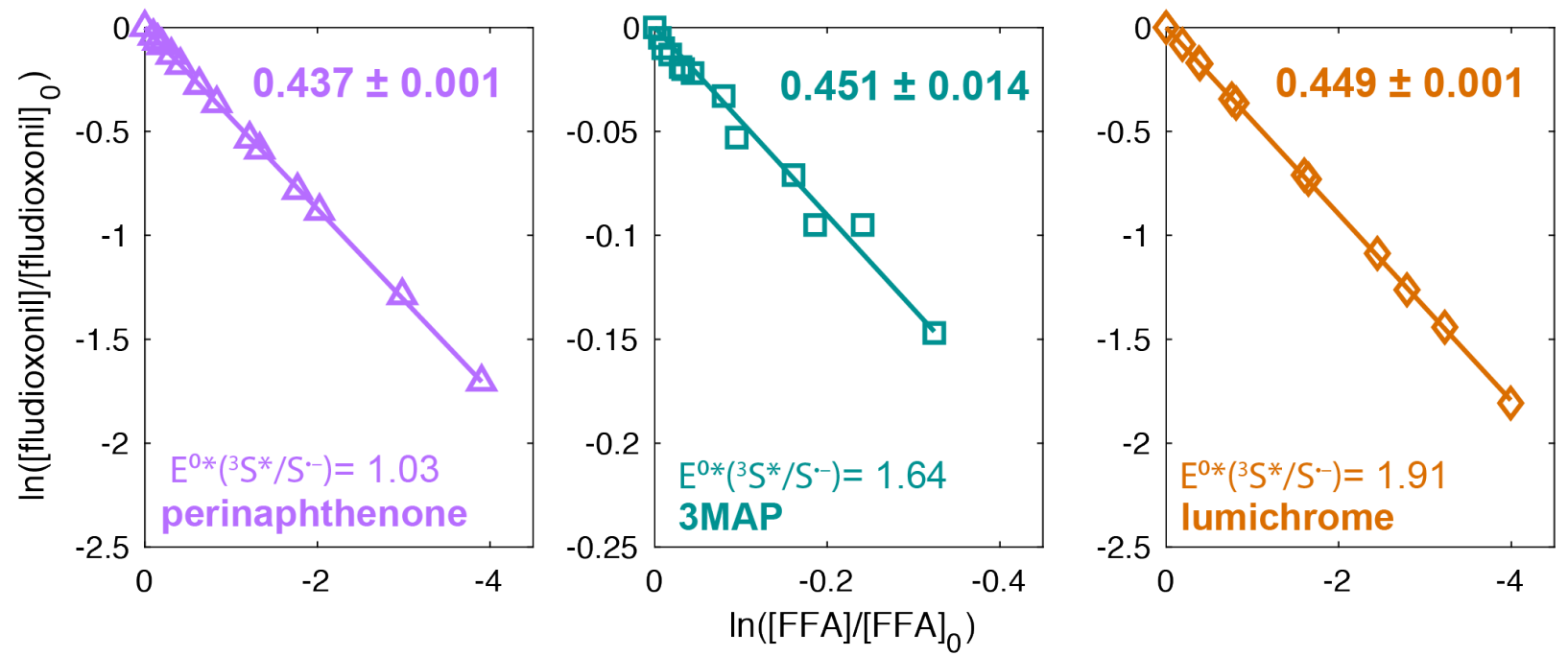

Figure S10. Degradation kinetics of fludioxonil (top row) or 3-cyanopyrrole (bottom row) plotted against degradation of FFA in the same solution using the model sensitizers perinaphthenone (PN, left), 3-methoxyacetephenone (3MAP, middle), and lumichrome (LC, right). 
NMR and Mass Spectra of Fludioxonil and Photoproducts

Table S2. ${ }^{1} \mathrm{H}$ NMR data of fludioxonil and products $\mathbf{2}, \mathbf{3}$, and 4 in $\mathrm{CDCl}_{3}(400 \mathrm{MHz})$.

\begin{tabular}{|c|c|c|c|c|}
\hline proton & $\begin{array}{c}\text { fludioxonil } \\
\delta_{H} \text { mult. }(J \text { in } \mathrm{Hz})\end{array}$ & $\begin{array}{c}2 \\
\delta_{H} \text { mult. }(J \text { in } \mathrm{Hz})\end{array}$ & $\begin{array}{c}3 \\
\delta_{H} \text { mult. }(J \text { in } \mathrm{Hz})\end{array}$ & $\begin{array}{c}4 \\
\delta_{H} \text { mult. }(J \text { in } \mathrm{Hz})\end{array}$ \\
\hline 1 & $7.43 \mathrm{dd}(3.1,2.1)$ & $5.83 \mathrm{~s}$ & - & - \\
\hline 4 & $7.35 \mathrm{dd}(2.7,2.1)$ & - & $6.85 \mathrm{~s}$ & - \\
\hline 6 & $7.72 \mathrm{dd}(8.1,1.0)$ & $7.42 \mathrm{dd}(6.9,2.4)$ & $7.92 \mathrm{dd}(7.5,1.9)$ & $7.53 \mathrm{dd}(8.1,1.2)$ \\
\hline 7 & $7.16 \mathrm{t}(8.1)$ & $7.20 \mathrm{~m}$ & $7.34 \mathrm{~m}$ & $7.28 \mathrm{t}(8.1)$ \\
\hline 8 & $6.99 \mathrm{dd}(8.1,1.0)$ & $7.22 \mathrm{~m}$ & $7.35 \mathrm{~m}$ & $7.33 \mathrm{dd}(8.1,1.2)$ \\
\hline $\mathrm{N}-\mathrm{H}$ & $8.74 \mathrm{br} \mathrm{s}$ & $6.90 \mathrm{~s}$ & $7.27 \mathrm{~s}$ & 7.65 br s \\
\hline $\mathrm{O}-\mathrm{H}$ & & 3.37 br s & 4.12 br s & . \\
\hline
\end{tabular}

Table S3. ${ }^{13} \mathrm{C}$ NMR data of fludioxonil and products 2 and 4 in $\mathrm{CDCl}_{3}(100 \mathrm{MHz})$.

\begin{tabular}{|cccc|} 
& fludioxonil & $\mathbf{2}$ & $\mathbf{4}$ \\
carbon & $\delta_{\mathrm{c}}$ & $\delta_{\mathrm{c}}$ & $\delta_{\mathrm{C}}$ \\
\hline 1 & 127.4 & 78.5 & 162.8 \\
2 & 92.3 & 126.0 & 133.5 \\
3 & 118.6 & 141.3 & 144.7 \\
4 & 119.7 & 166.5 & 165.5 \\
5 & 116.3 & 110.6 & 109.4 \\
6 & 121.5 & 124.3 & 124.8 \\
7 & 124.2 & 124.0 & 124.4 \\
8 & 108 & 112.5 & 114.1 \\
9 & 143.8 & 144.0 & 144.5 \\
10 & 139.9 & 141.9 & 143.2 \\
11 & 131.4 & 131.4 & 131.3 \\
12 & 116.2 & 111.9 & 109.3 \\
\hline
\end{tabular}

Table S4. HMBC correlations for fludioxonil and products 2 and 4 in $\mathrm{CDCl}_{3}(400 \mathrm{MHz})$.

\begin{tabular}{cccc} 
& fludioxonil & $\mathbf{2}$ & $\mathbf{4}$ \\
proton & $\mathrm{H \# \rightarrow C \#}$ & $\mathrm{H \# \rightarrow C \#}$ & $\mathrm{H \# \rightarrow C \#}$ \\
\hline 1 & $2,3,4$ & $2,3,4,12$ & - \\
4 & $1,2,3$ & - & - \\
6 & $3,5,8,10$ & $3,5,7,8,10$ & $3,8,10$ \\
7 & $5,6,8,9$ & $5,6,8,9$ & $5,6,9$ \\
8 & $6,7,9,10$ & $6,7,9,10$ & $6,7,9,10$ \\
$\mathrm{~N}-\mathrm{H}$ & - & $1,2,3$ & - \\
\hline
\end{tabular}




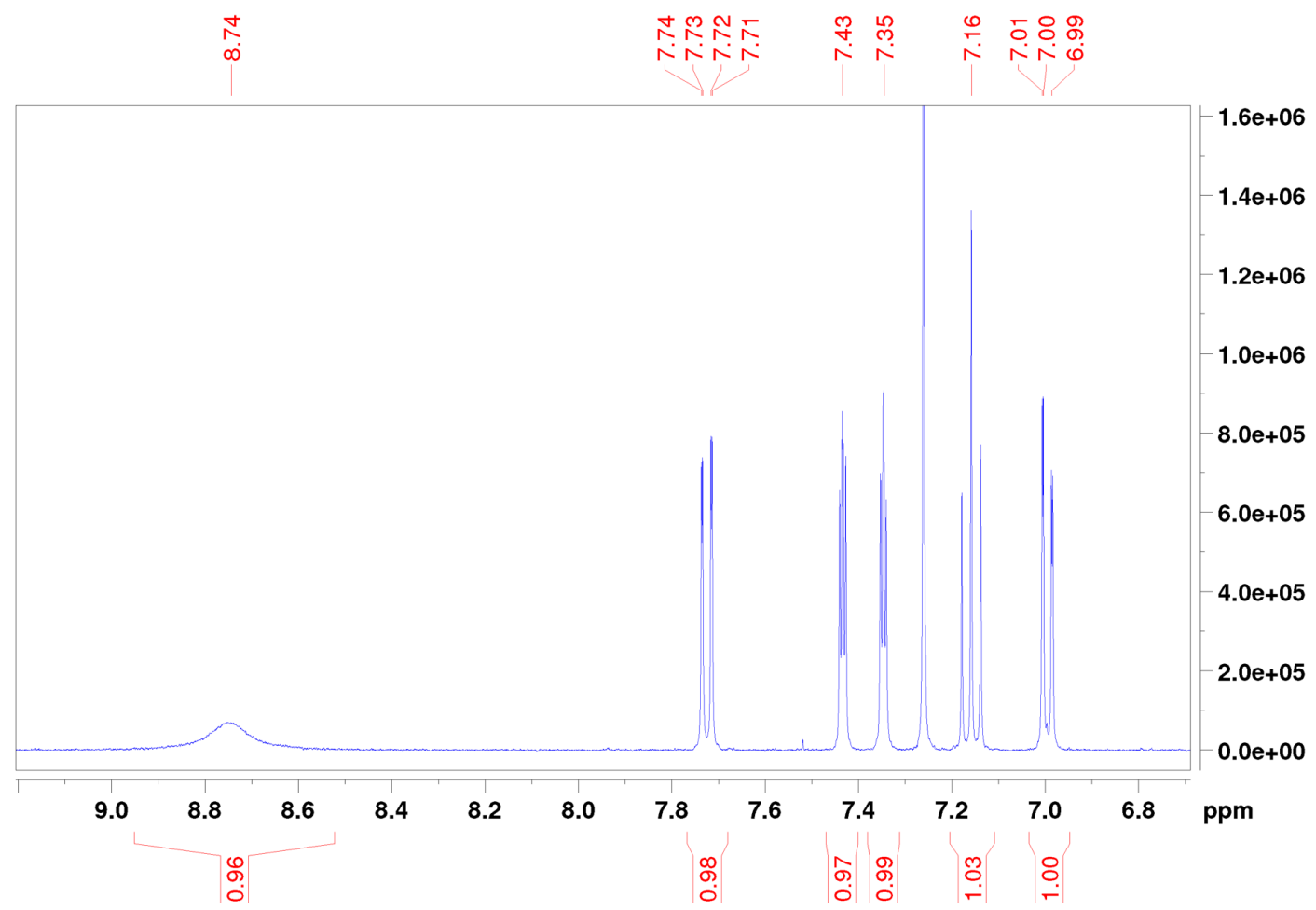

Figure S11. ${ }^{1} \mathrm{H}$ NMR spectrum of fludioxonil standard in $\mathrm{CDCl}_{3}(400 \mathrm{MHz})$.

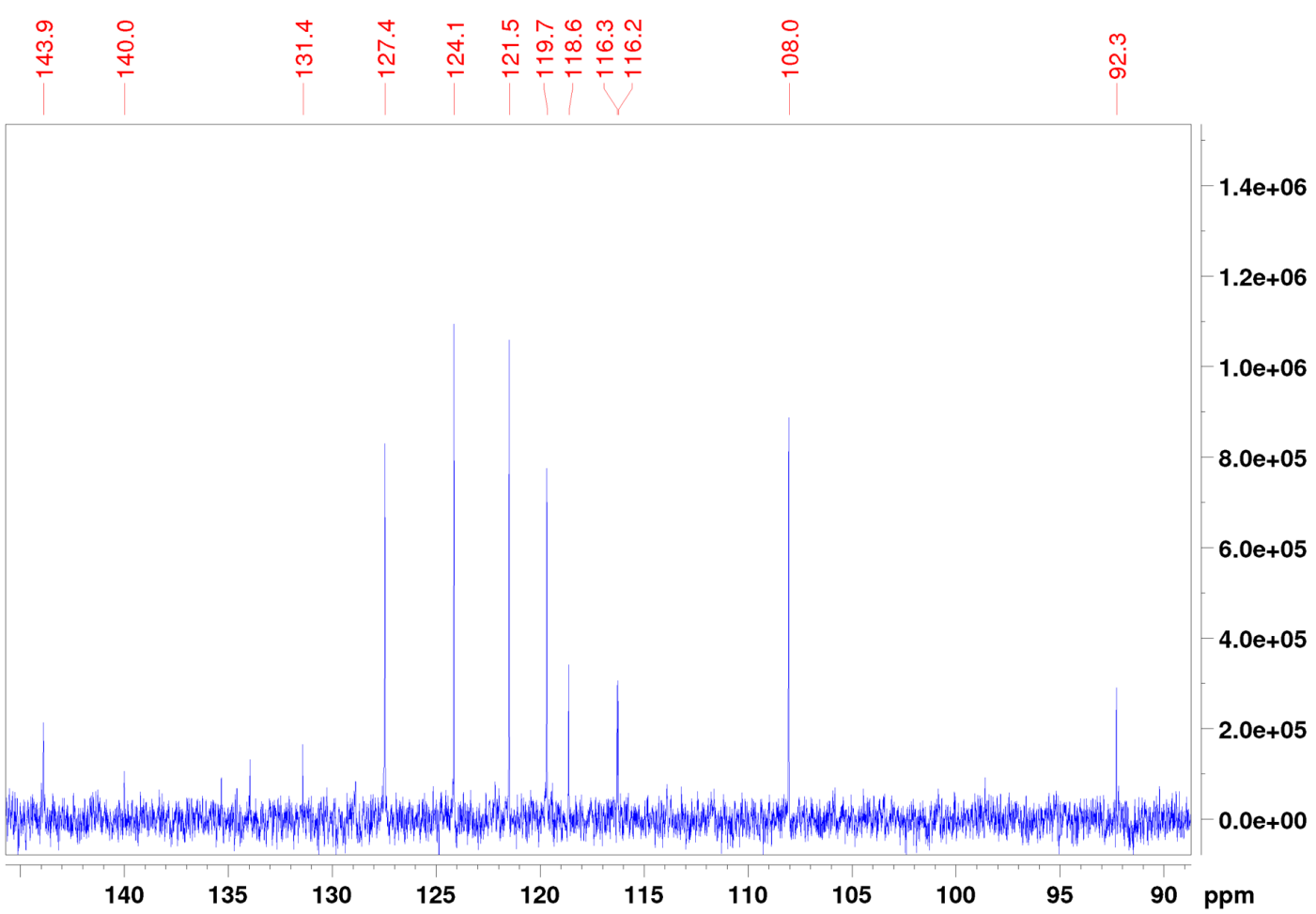

Figure S12. ${ }^{13} \mathrm{C}$ NMR spectrum of fludioxonil standard in $\mathrm{CDCl}_{3}(100 \mathrm{MHz})$. 


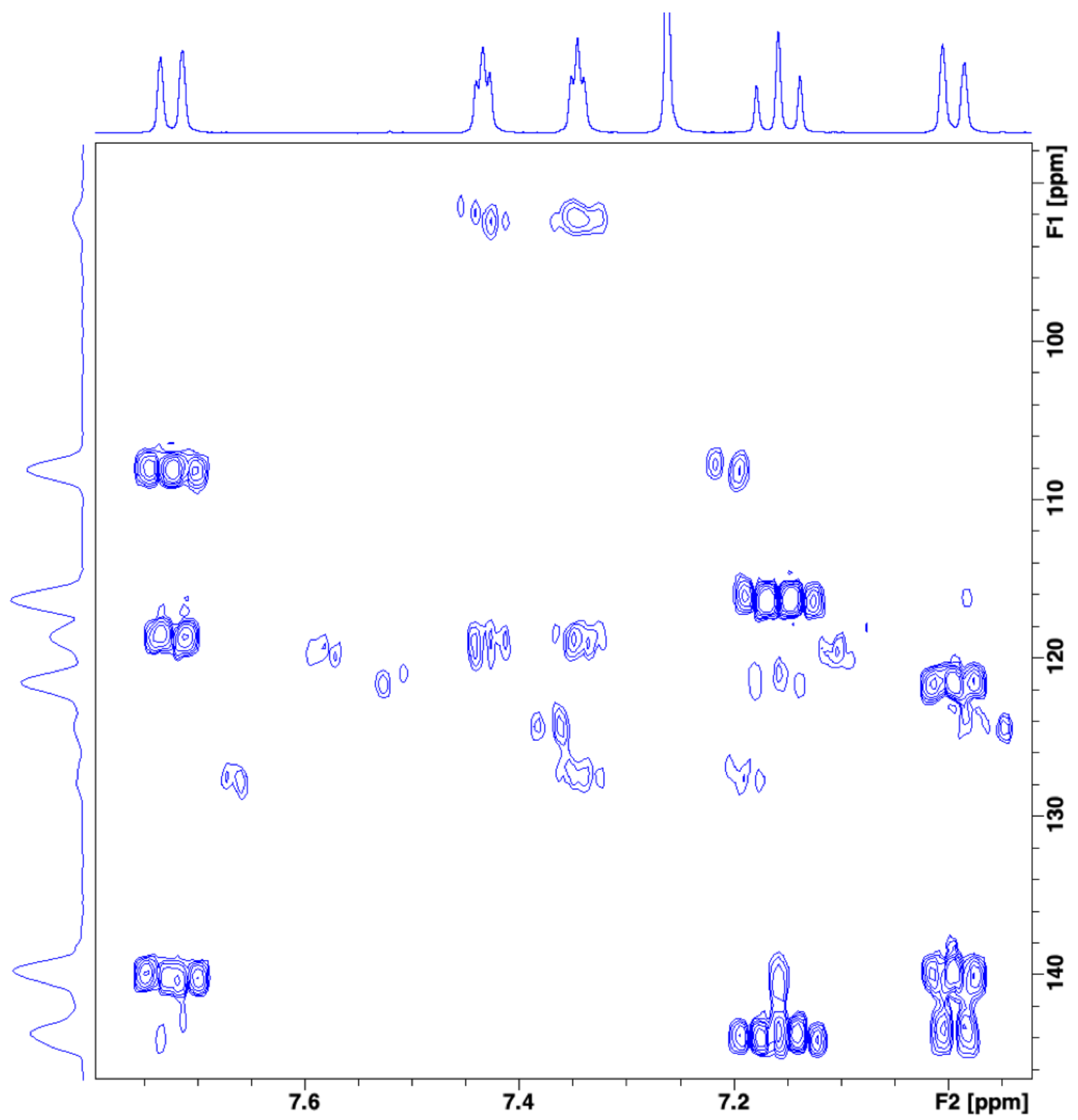

Figure S13. HMBC spectrum of fludioxonil standard in $\mathrm{CDCl}_{3}(400 \mathrm{MHz})$. 


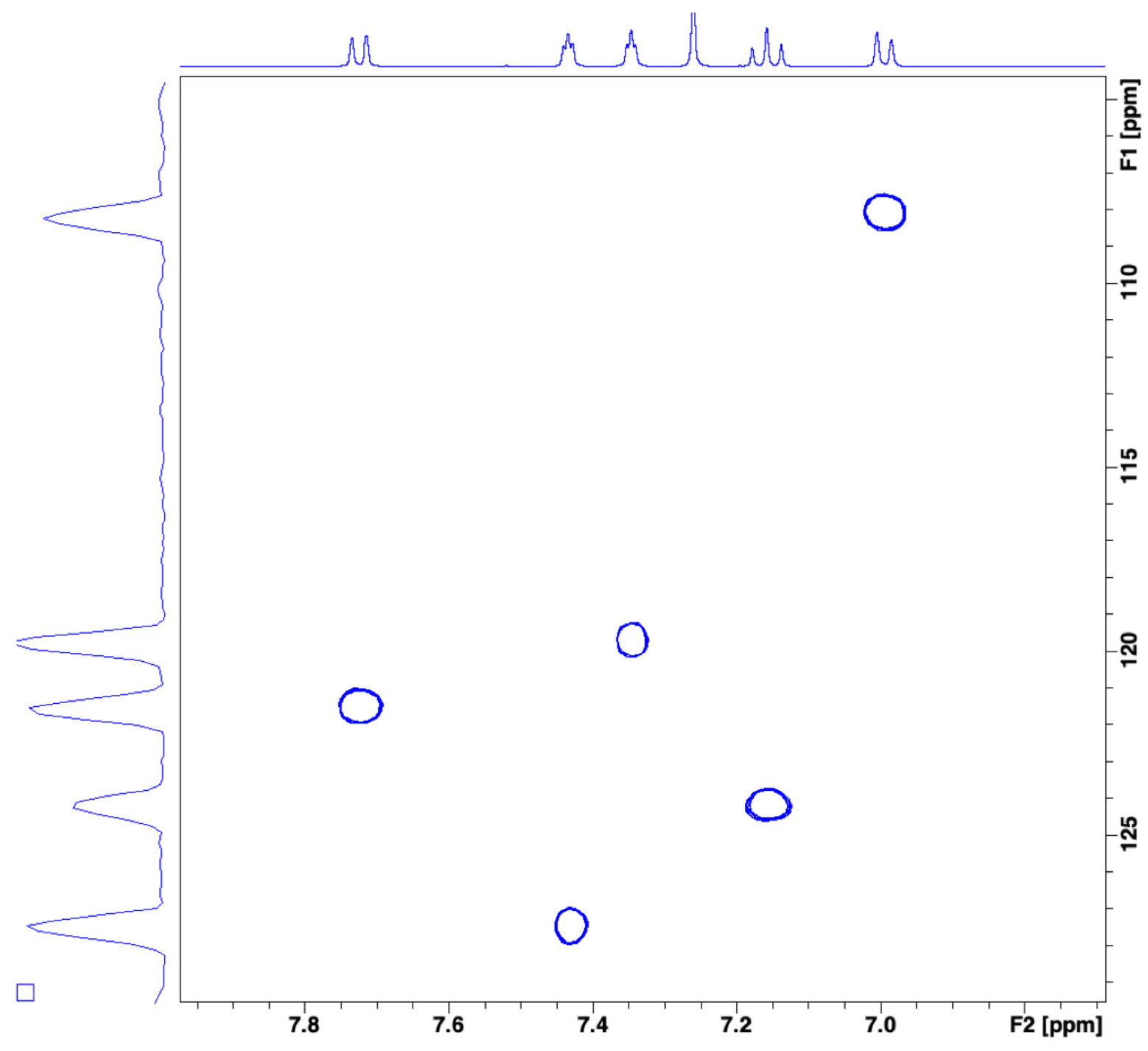

Figure S14. HSQC spectrum of fludioxonil standard in $\mathrm{CDCl}_{3}(400 \mathrm{MHz})$. 


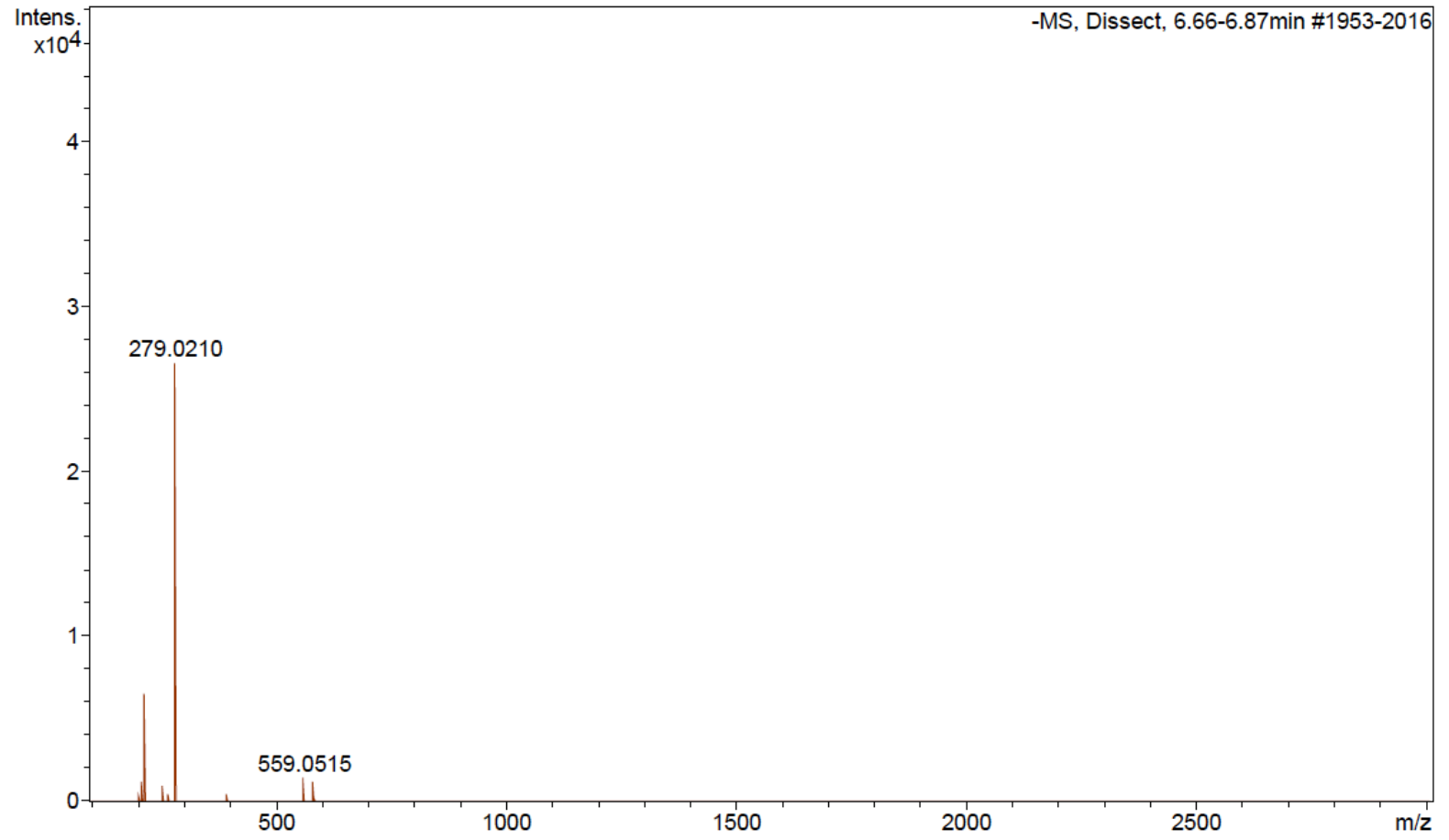

Figure S15. HRMS spectrum of fludioxonil photoproduct 1.

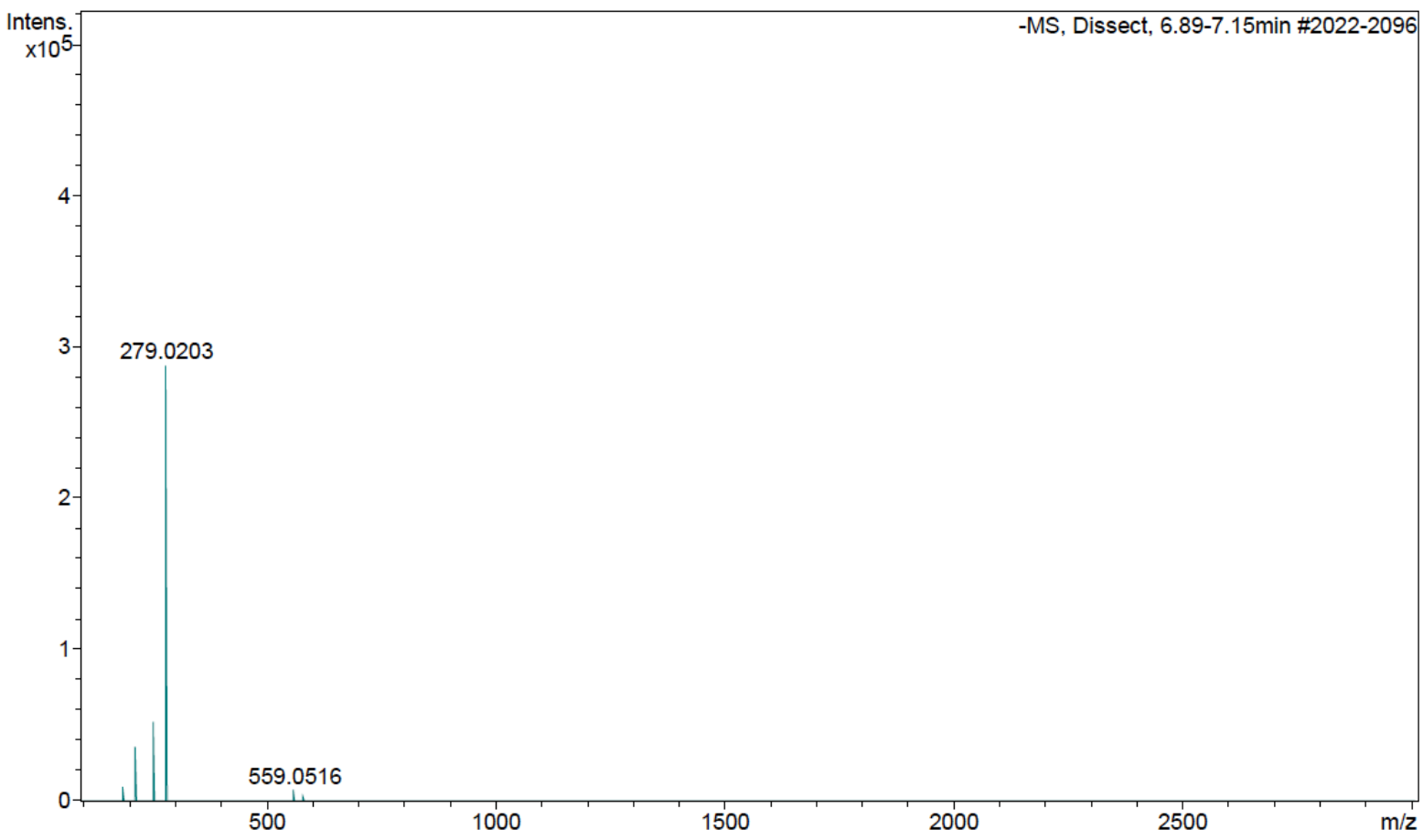

Figure S16. HRMS spectrum of fludioxonil photoproduct 2. 


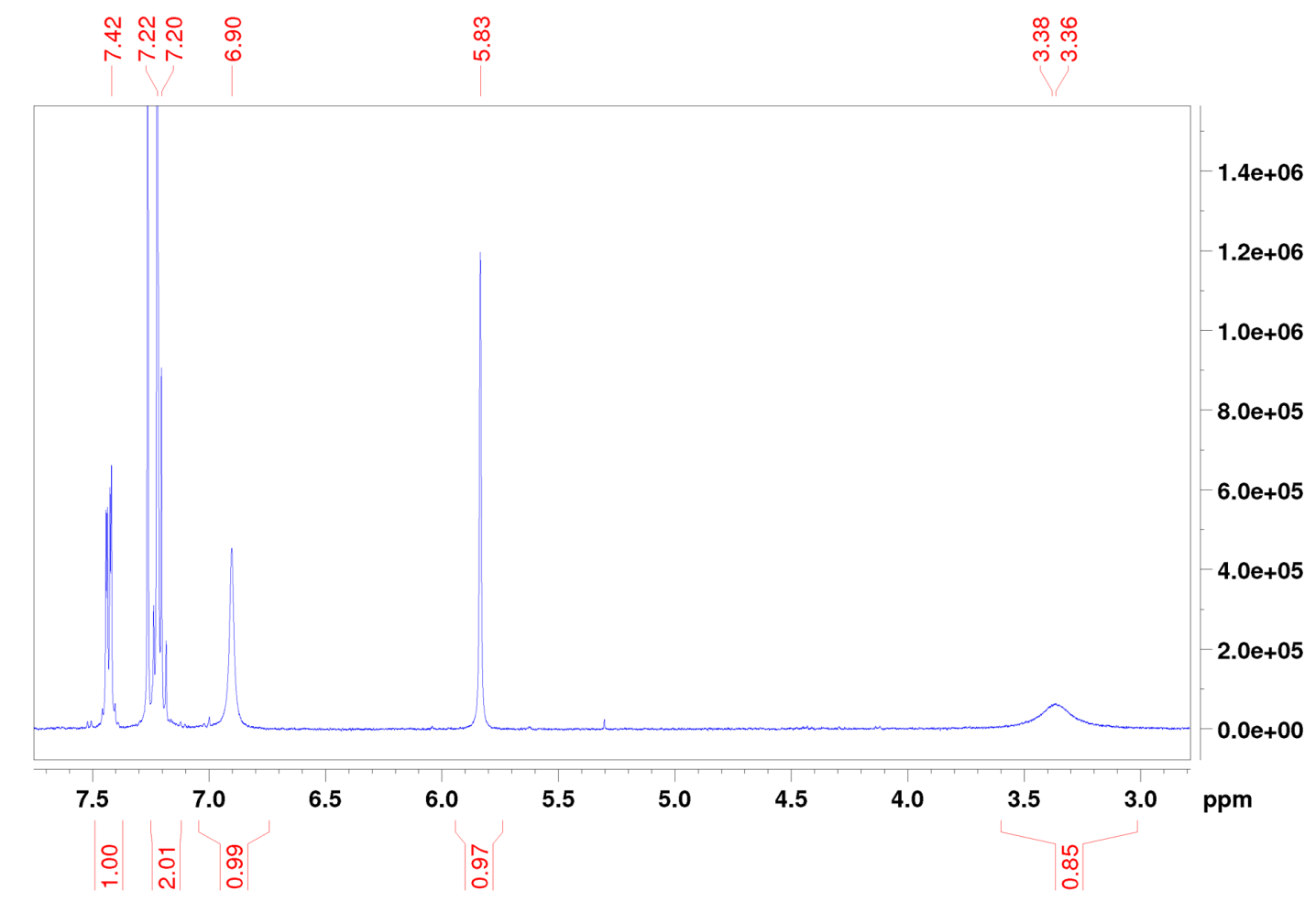

Figure S17. ${ }^{1} \mathrm{H}$ NMR spectrum of fludioxonil photoproduct 2 in $\mathrm{CDCl}_{3}(400 \mathrm{MHz})$.

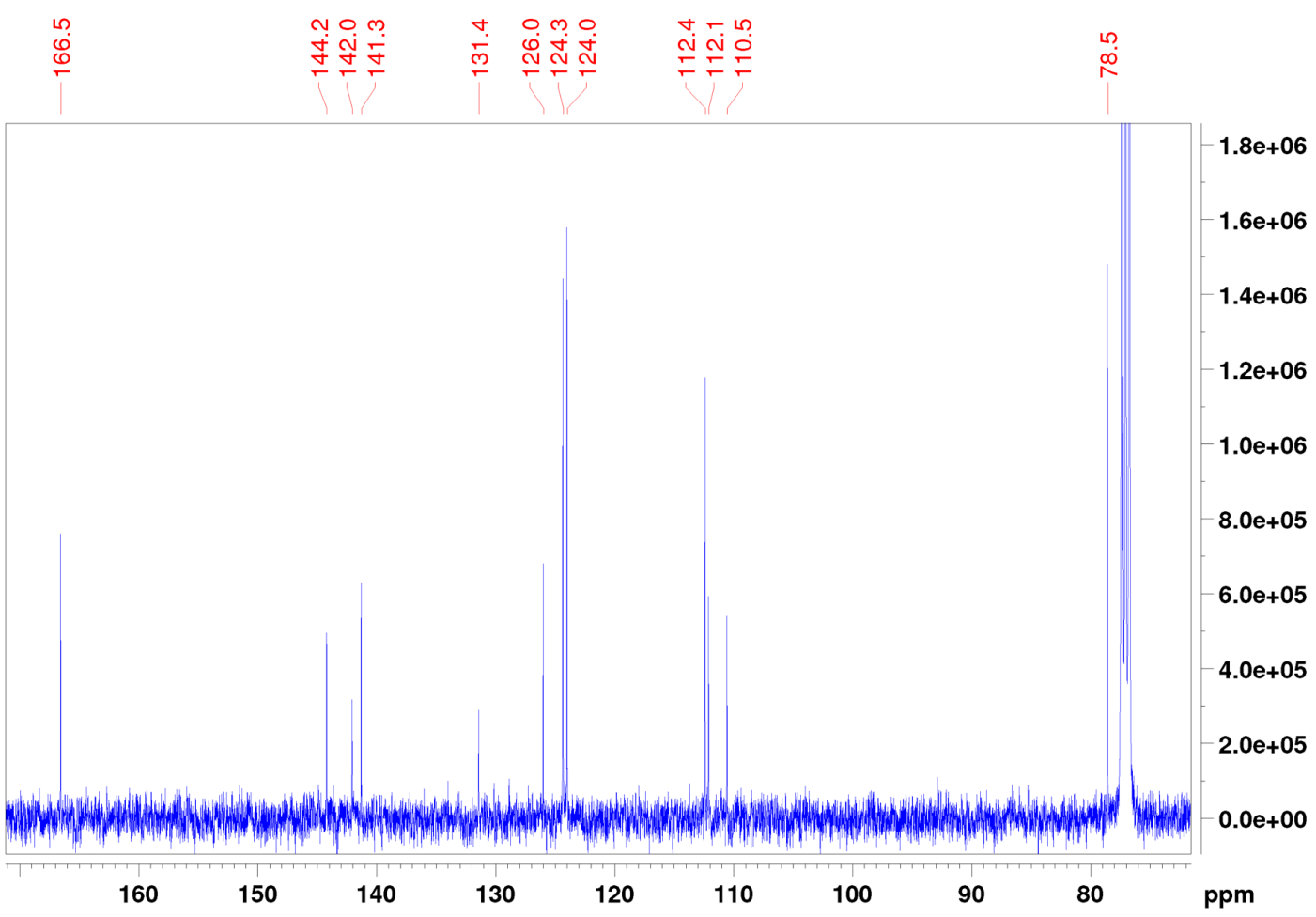

Figure S18. ${ }^{13} \mathrm{C}$ NMR spectrum of fludioxonil photoproduct 2 in $\mathrm{CDCl}_{3}(100 \mathrm{MHz})$. 


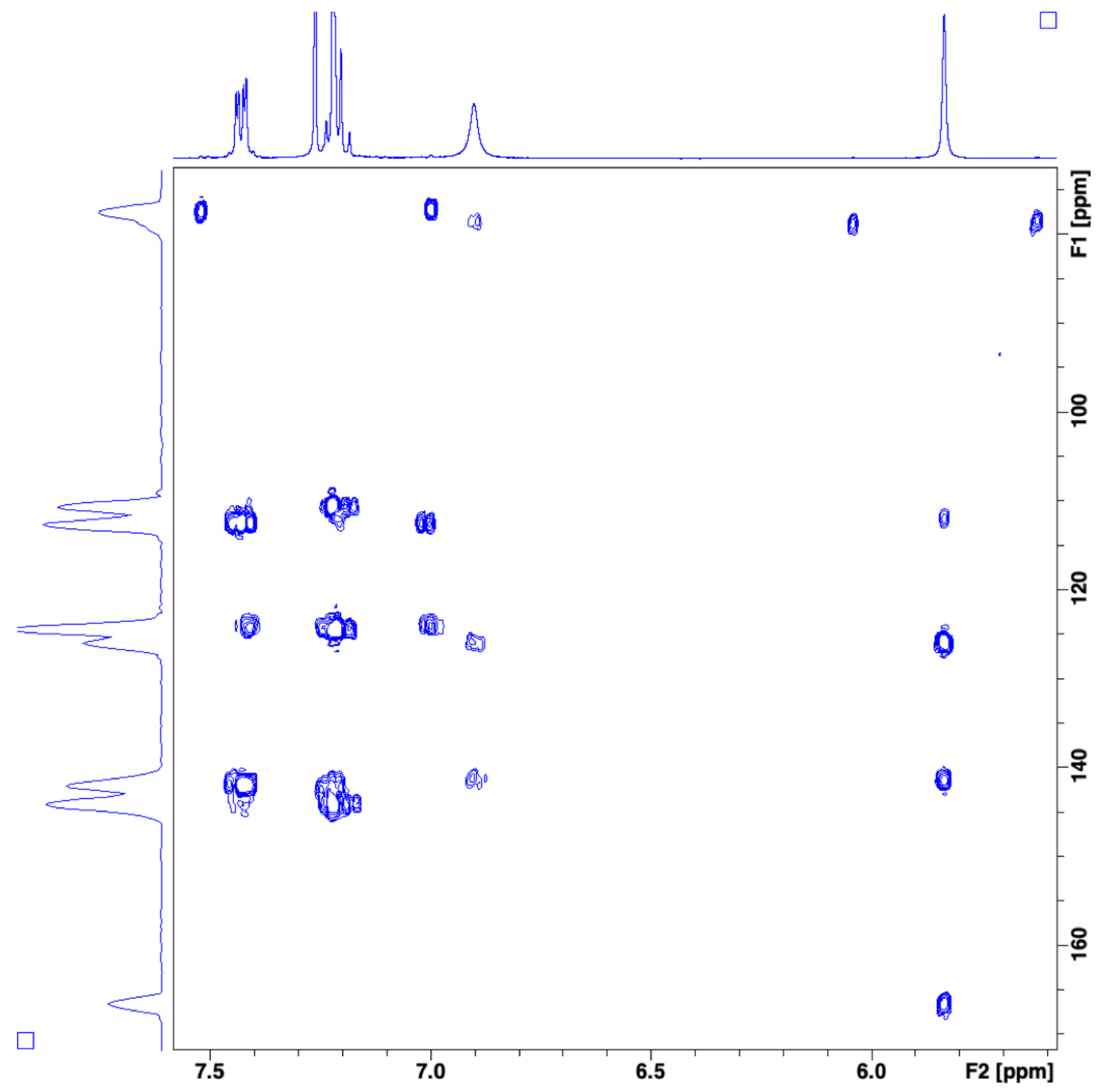

Figure S19. HMBC spectrum of fludioxonil photoproduct 2 in $\mathrm{CDCl}_{3}(400 \mathrm{MHz})$. 


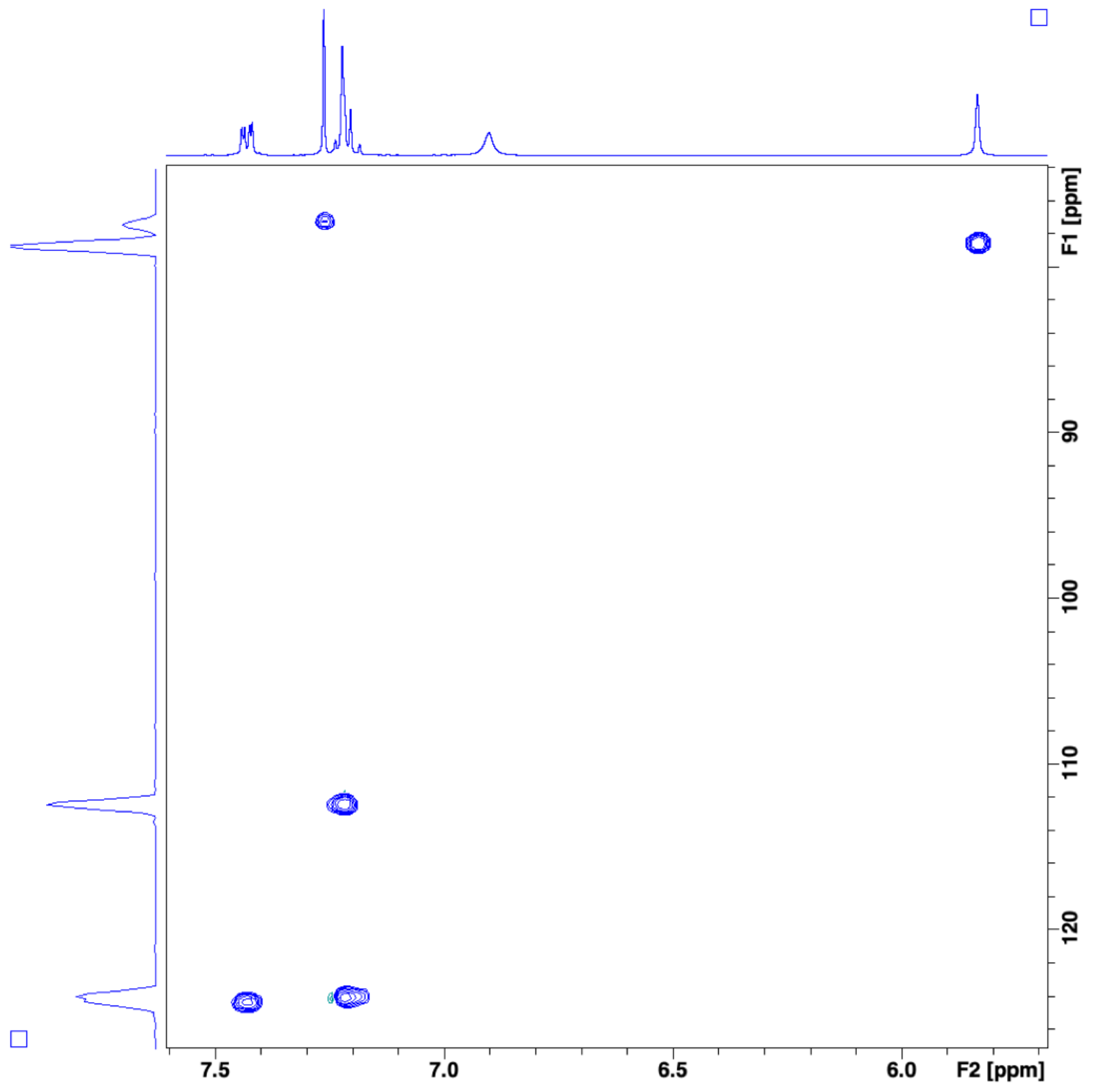

Figure S20. HSQC spectrum of fludioxonil photoproduct 2 in $\mathrm{CDCl}_{3}(400 \mathrm{MHz})$. 


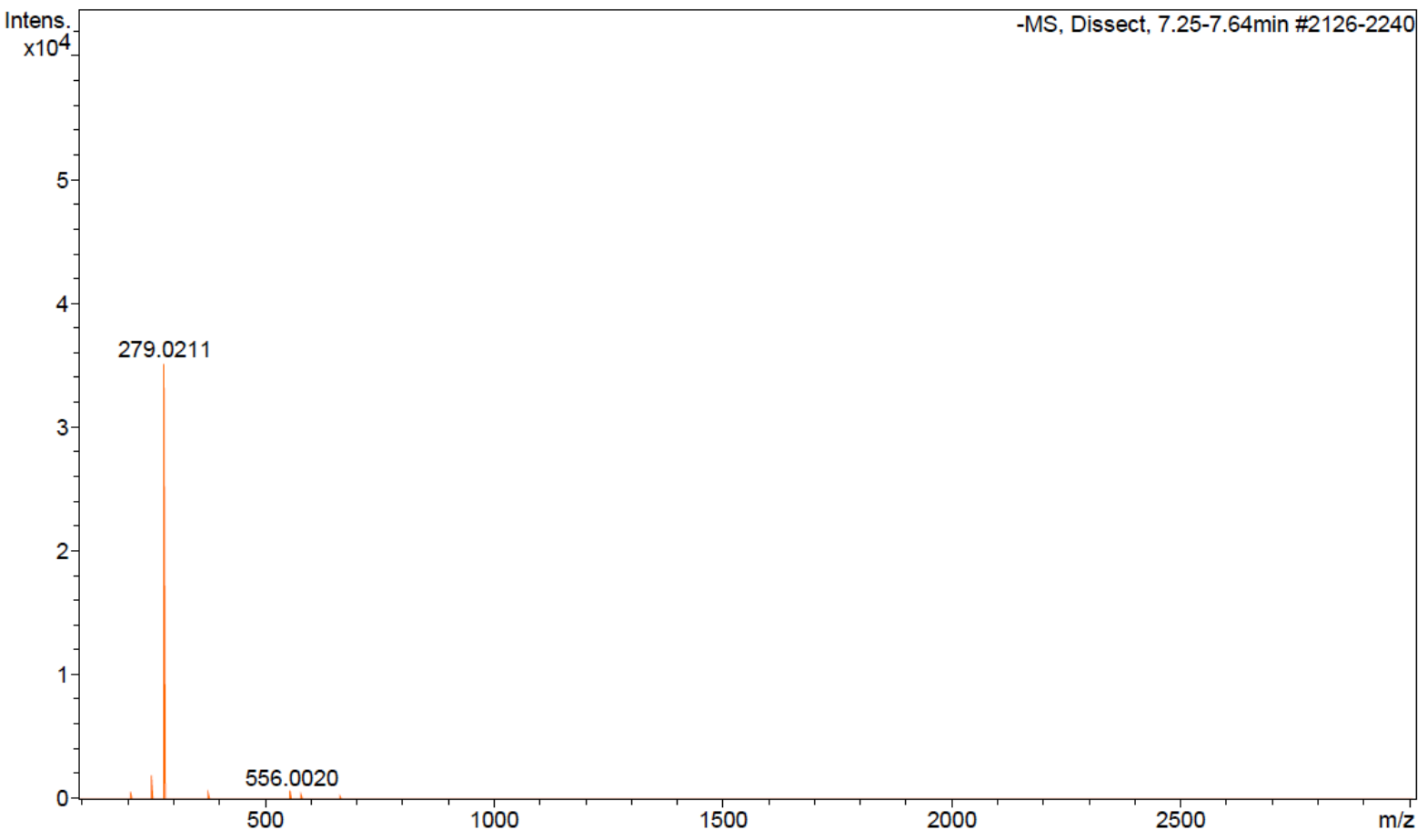

Figure S21. HRMS spectrum of fludioxonil photoproduct 3.

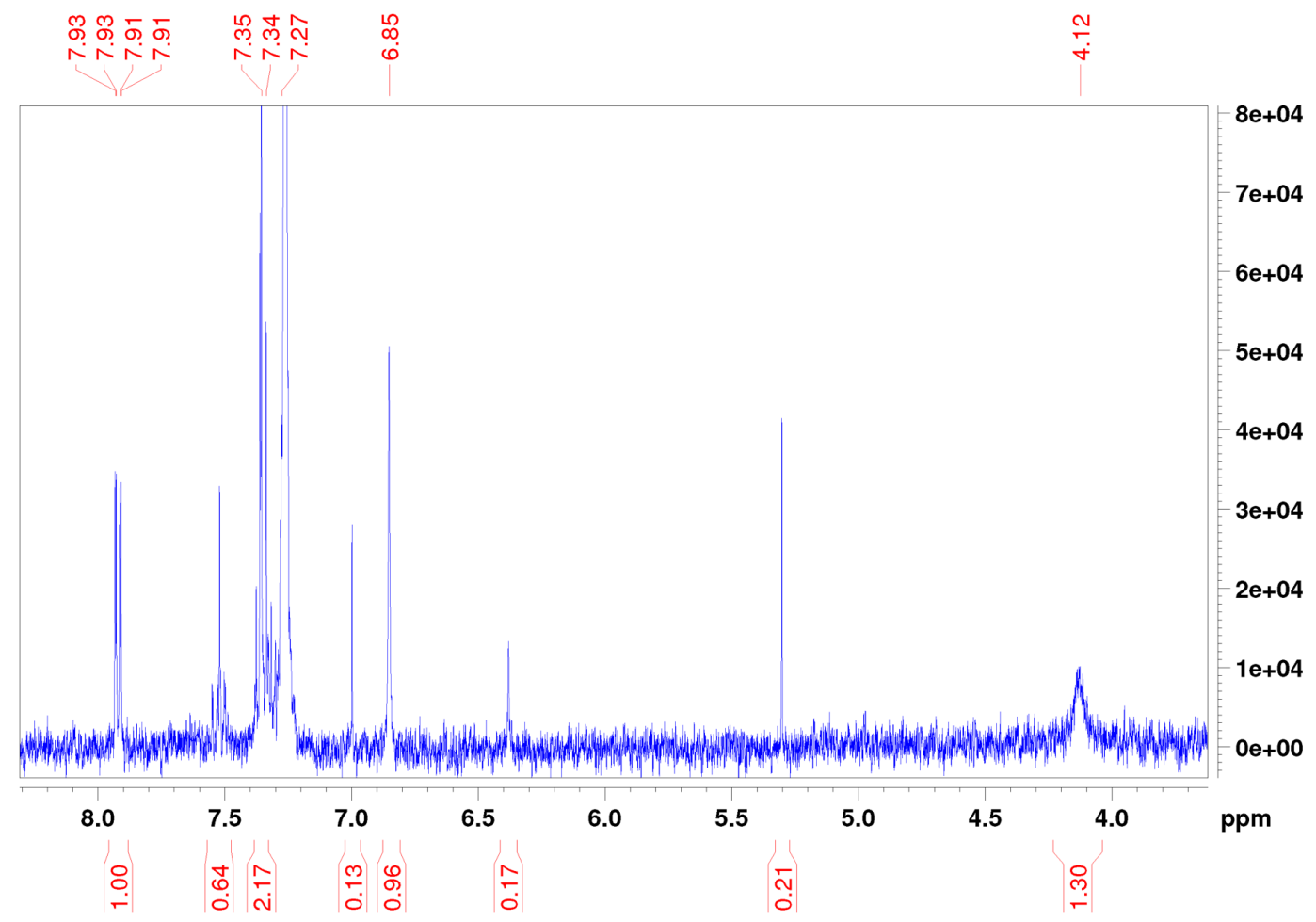

Figure S22. ${ }^{1} \mathrm{H}$ NMR spectrum of fludioxonil photoproduct 3 in $\mathrm{CDCl}_{3}(400 \mathrm{MHz})$. Minor proton signals are from an unidentified impurity. 


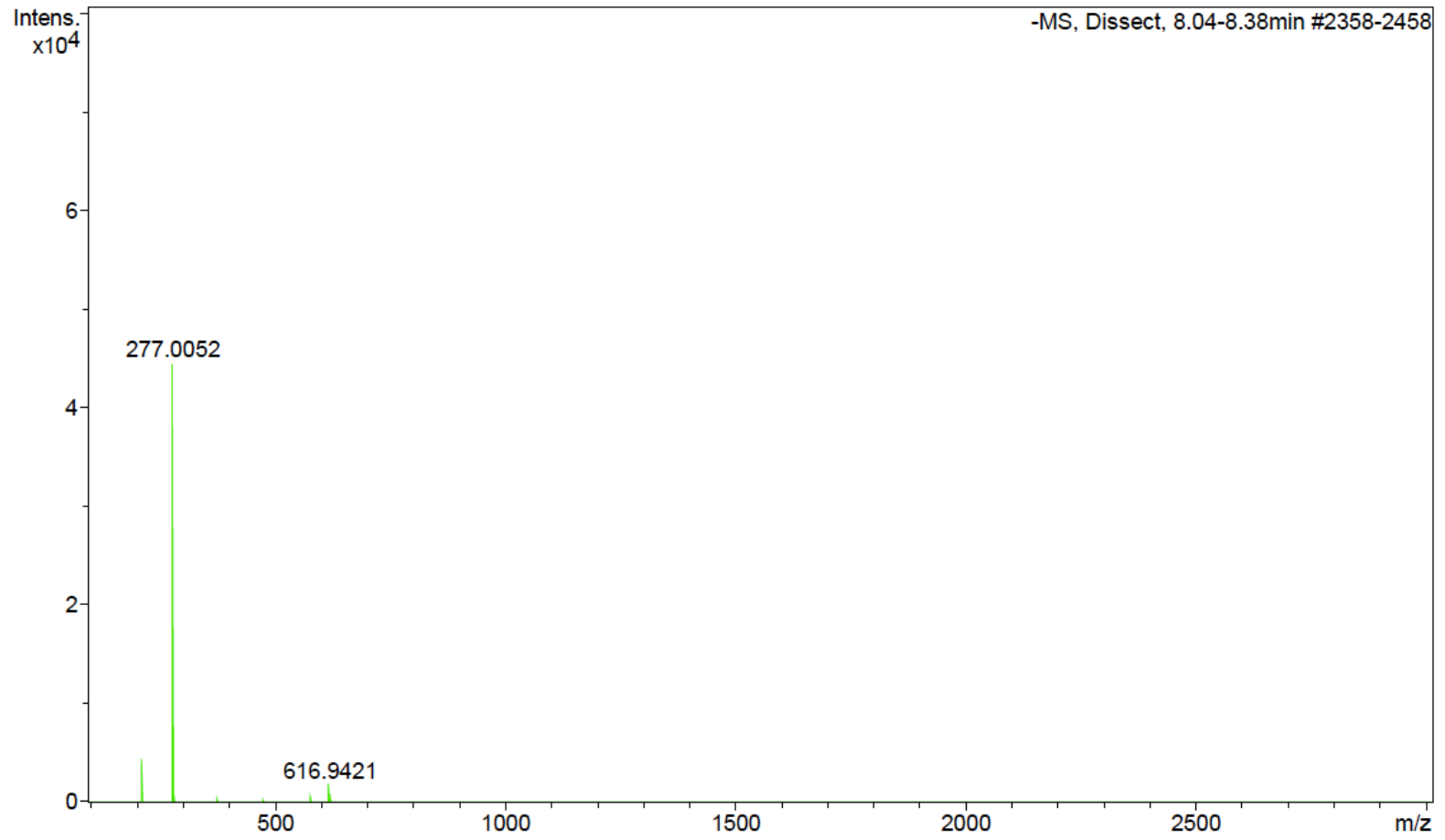

Figure S23. HRMS spectrum of fludioxonil photoproduct 4.

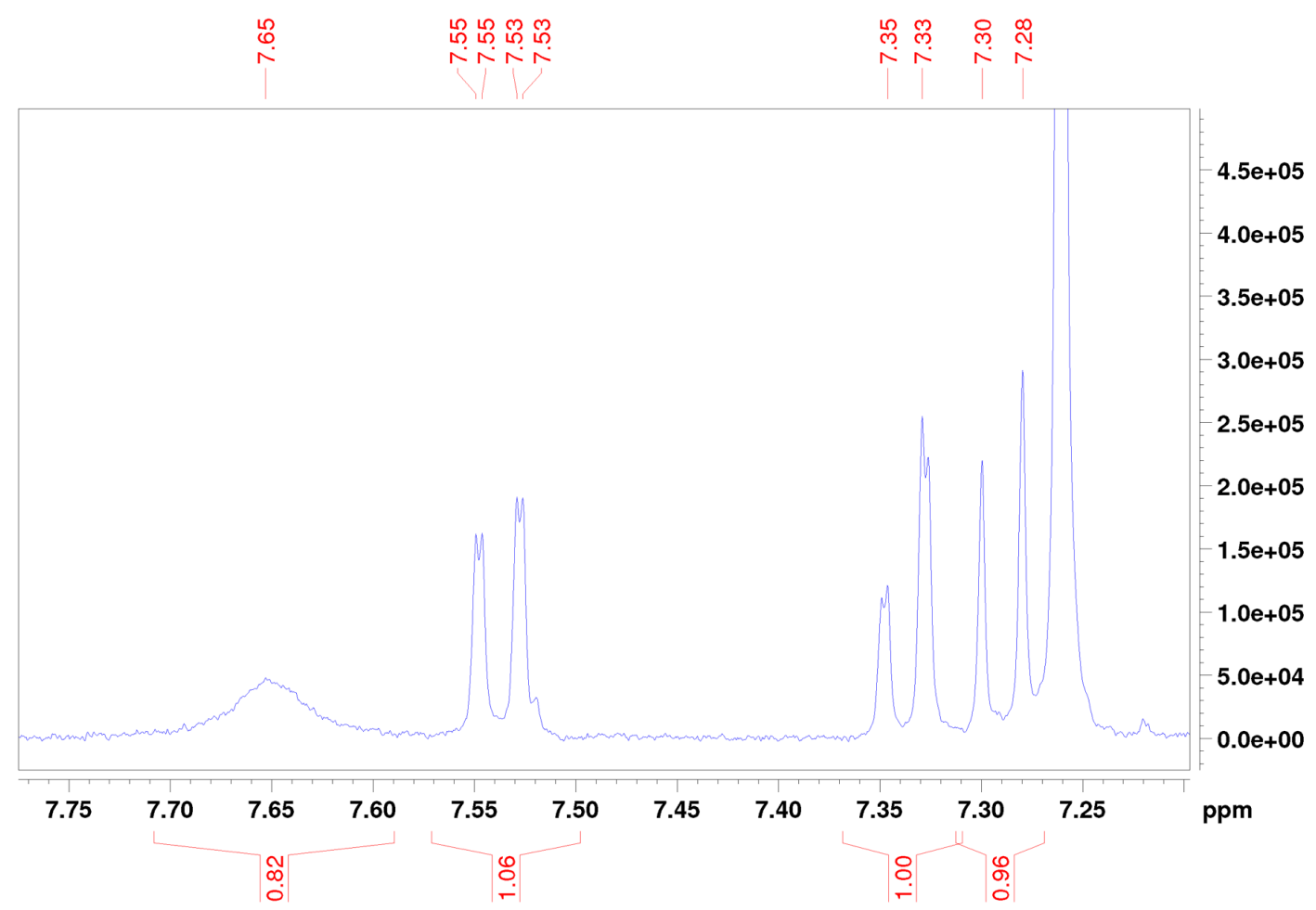

Figure S24. ${ }^{1} \mathrm{H}$ NMR spectrum of fludioxonil photoproduct 4 in $\mathrm{CDCl}_{3}(400 \mathrm{MHz})$. 


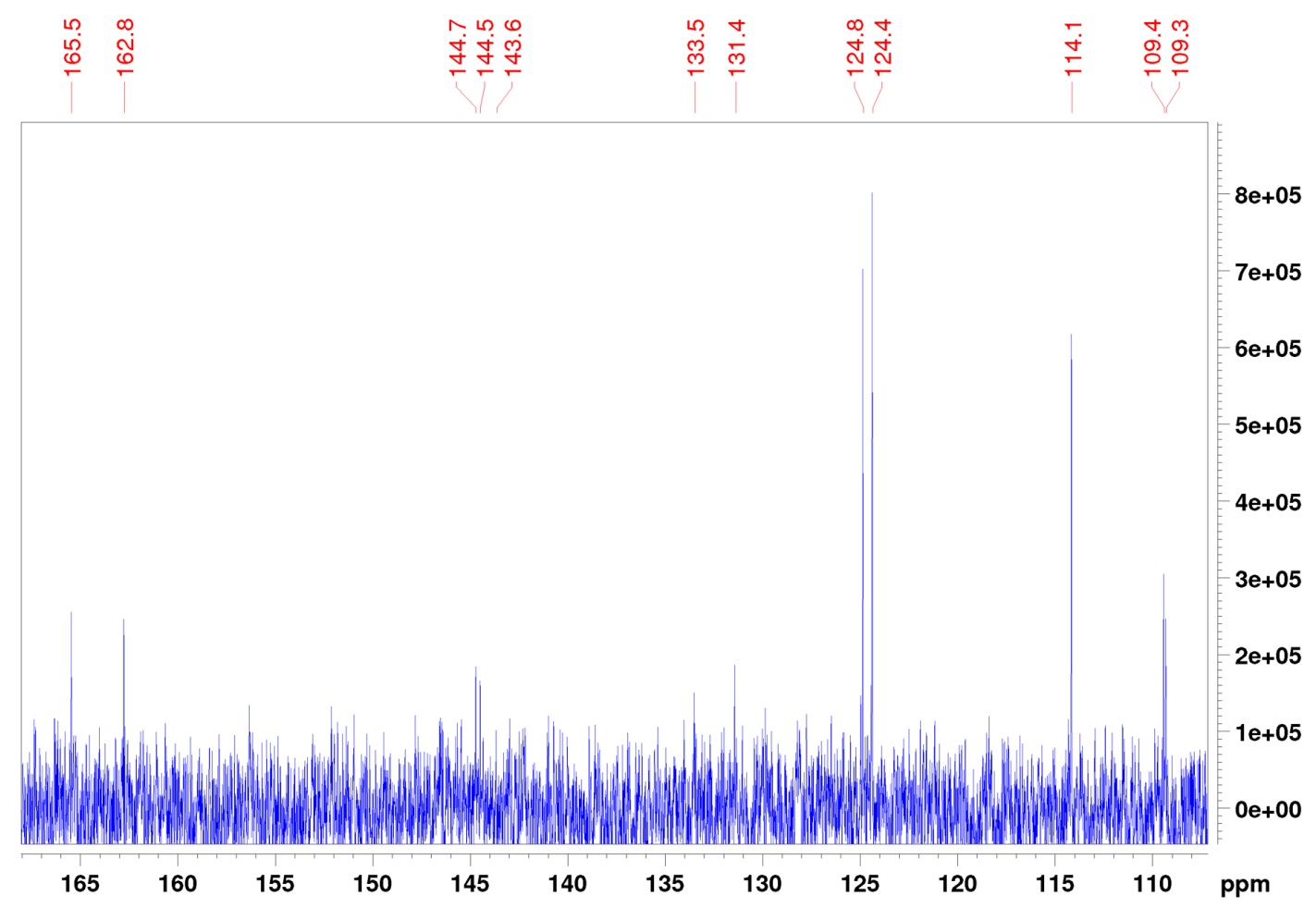

Figure S25. ${ }^{13} \mathrm{C}$ NMR spectrum of fludioxonil photoproduct 4 in $\mathrm{CDCl}_{3}(100 \mathrm{MHz})$. 


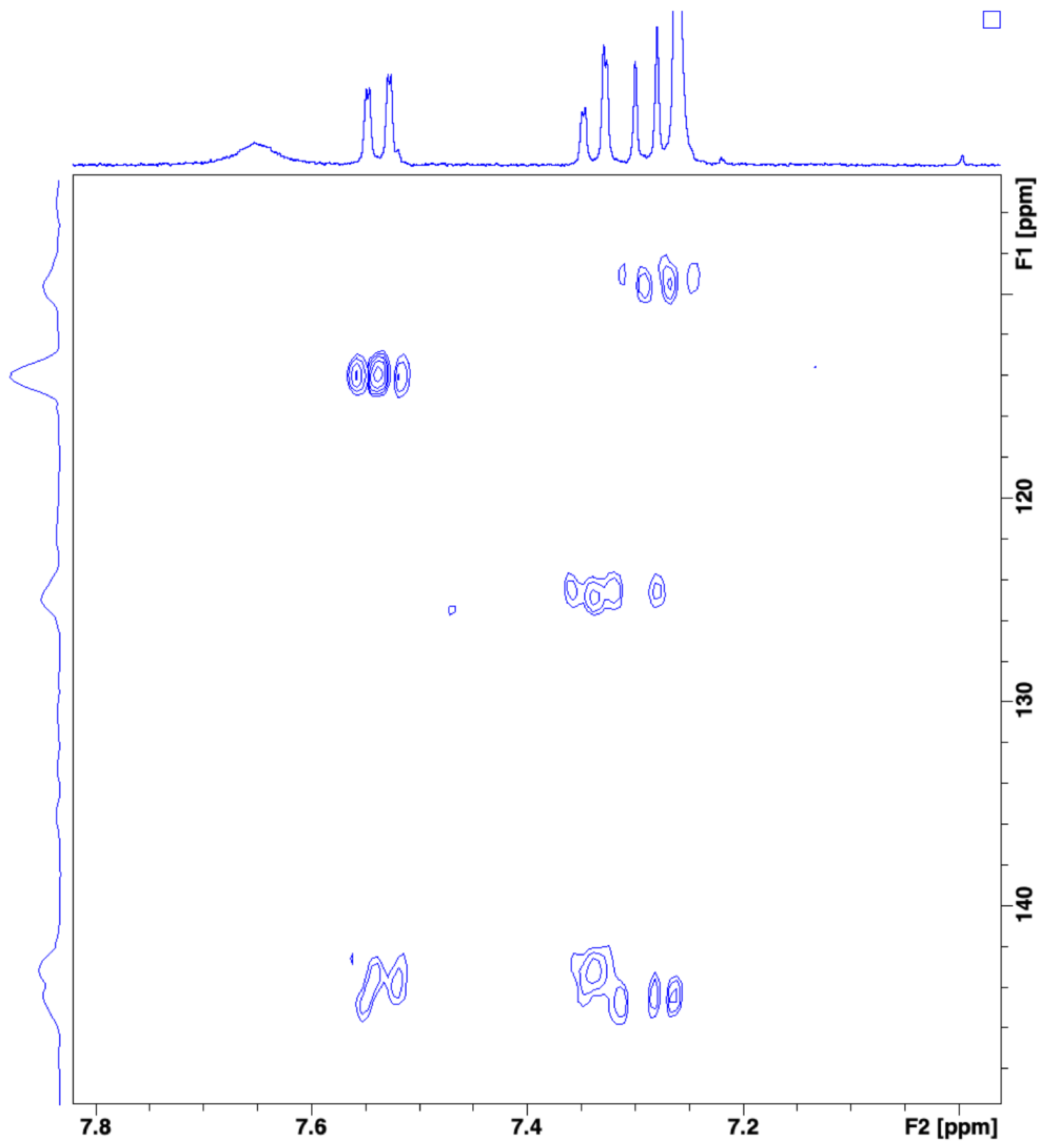

Figure S26. HMBC spectrum of fludioxonil photoproduct 4 in $\mathrm{CDCl}_{3}(400 \mathrm{MHz})$. 


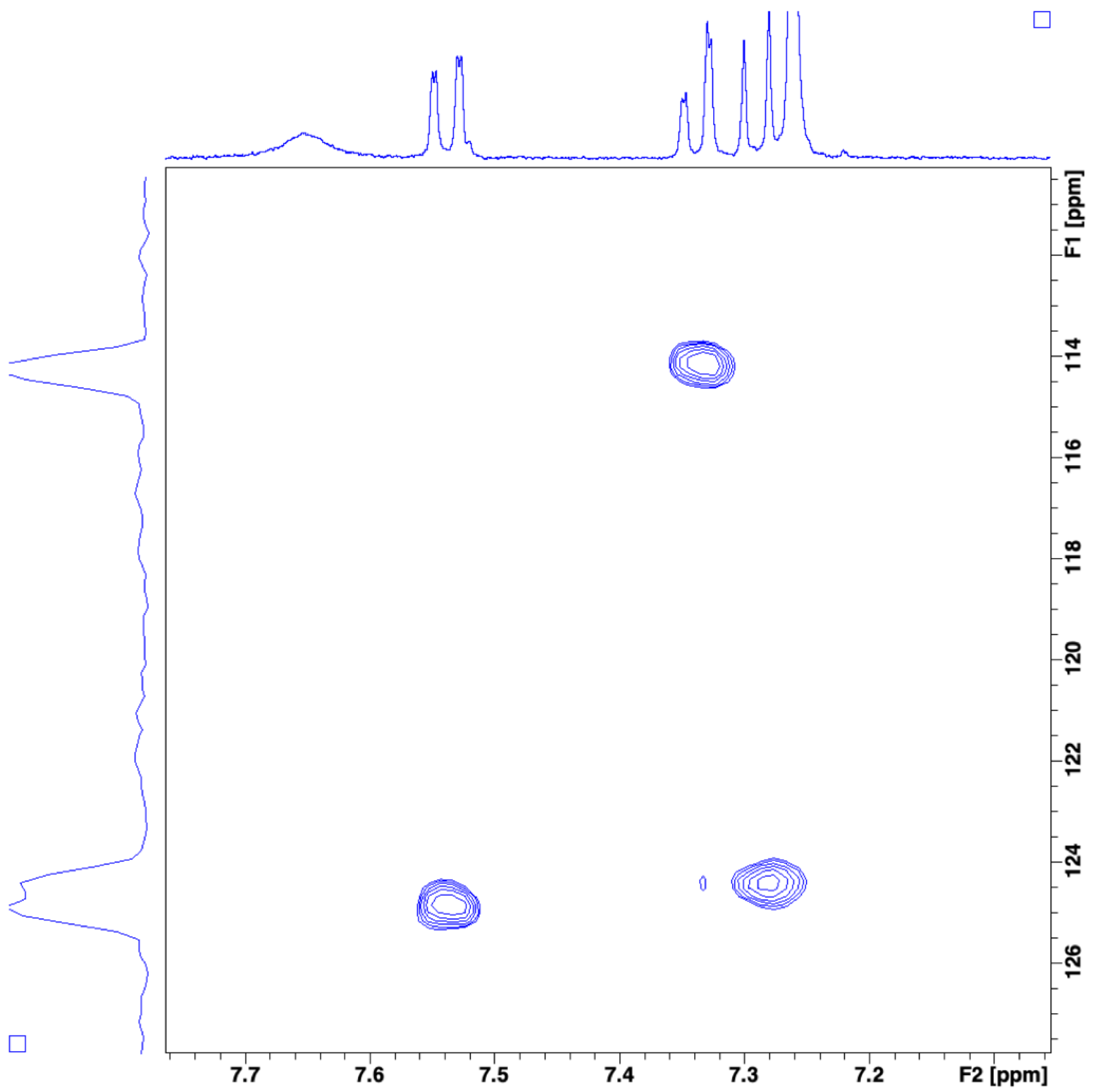

Figure S27. HSQC spectrum of fludioxonil photoproduct 4 in $\mathrm{CDCl}_{3}(400 \mathrm{MHz})$. 


\section{Photoproduct Formation}
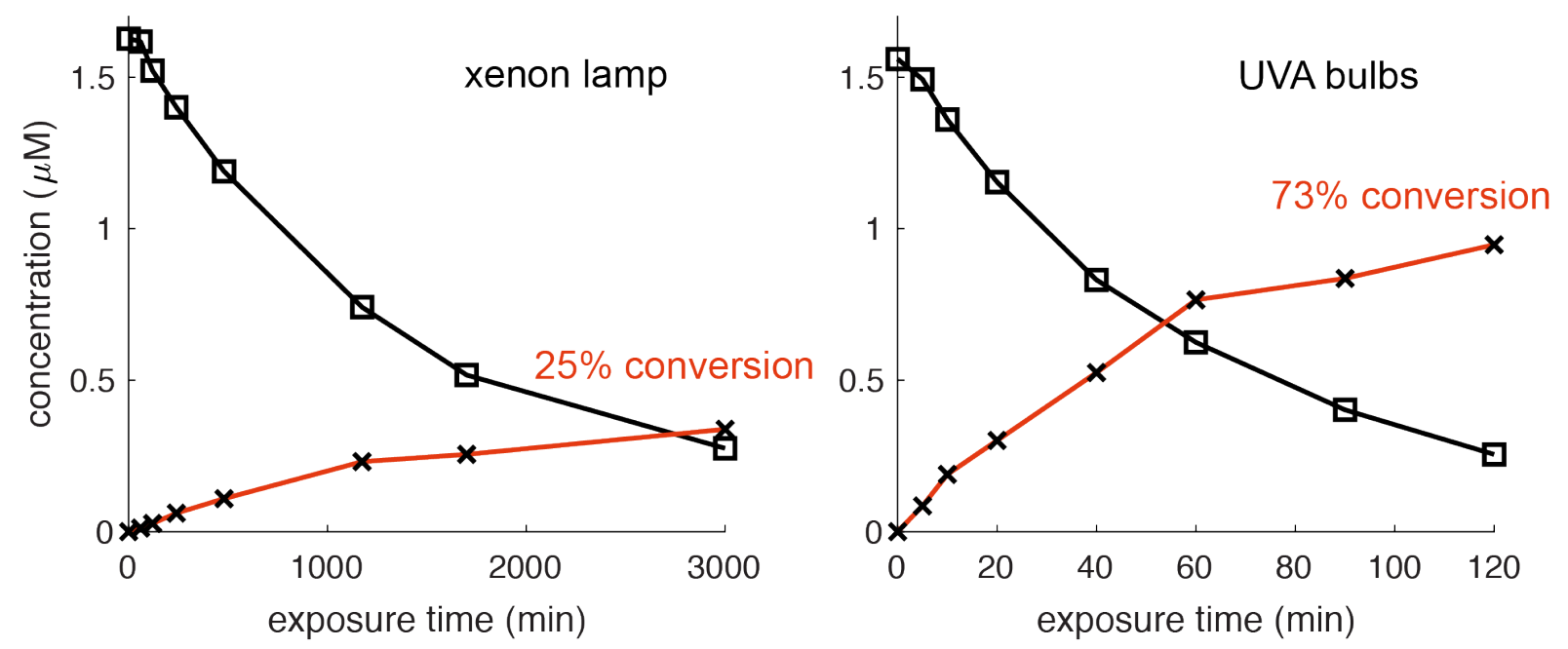

Figure S28. Degradation of fludioxonil (squares, black line) in solutions containing PN as a sensitizer and the formation of photoproduct 2 (x, red line) when irradiated with the xenon lamp where direct and indirect photodegradation occurs (left, $0.1 \mu \mathrm{MPN}$ ) and with UVA bulbs where indirect photodegradation with ${ }^{1} \mathrm{O}_{2}$ occurs (right, $1 \mu \mathrm{M} P N$ ).<smiles>N#Cc1c[nH]c(O)c1-c1cccc2c1OC(F)(F)O2</smiles><smiles>N#C/C(C=O)=C(\C(N)=O)c1cccc2c1OC(F)(F)O2</smiles>

$(\mathrm{M}-\mathrm{H})^{-} 279.0218$

Figure S29. Structure and calculated $(\mathrm{M}-\mathrm{H})^{-} \mathrm{m} / \mathrm{z}$ of potential fludioxonil hydroperoxide and allylic aldehyde photoproducts. 

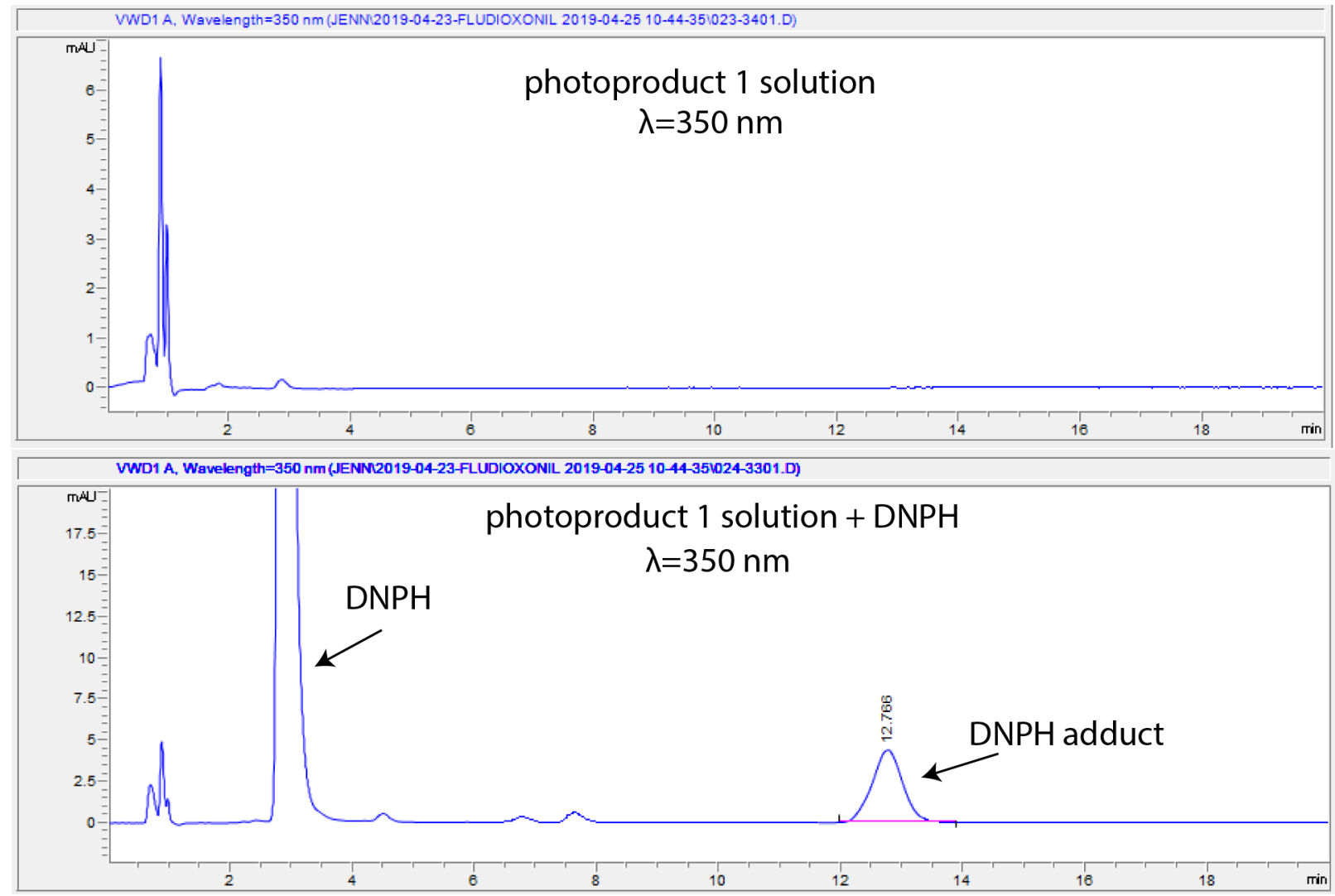

Figure S30. Chromatogram of fludioxonil photoproduct mixture at $\lambda=350 \mathrm{~nm}$ without the addition of the DNPH (top) and with the addition of the DNPH (bottom) 


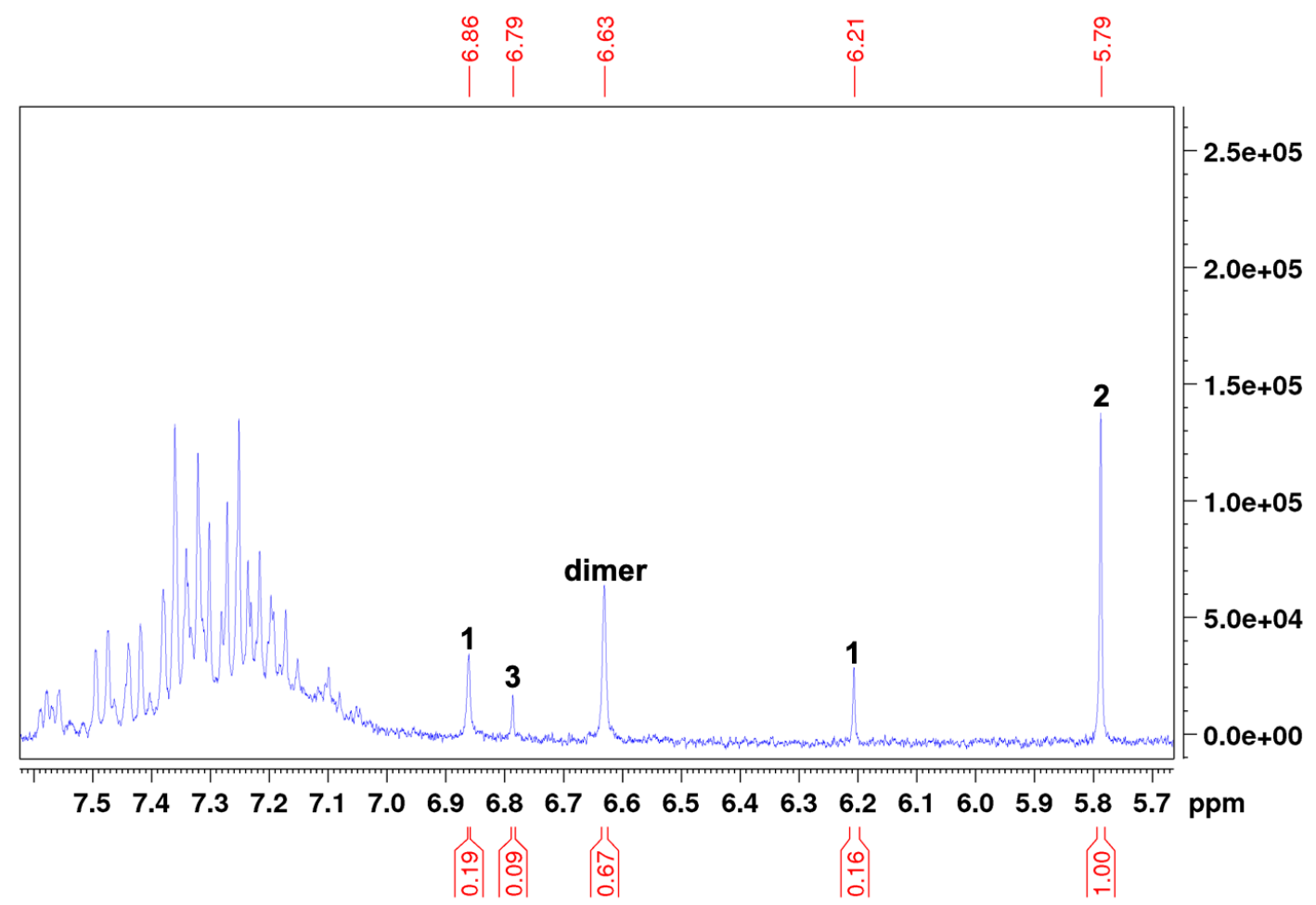

Figure S31. ${ }^{1} \mathrm{H}$ NMR spectrum of fludioxonil photolysis mixture in 50:50 $\mathrm{CD}_{3} \mathrm{CN}: \mathrm{D}_{2} \mathrm{O}(400$ $\mathrm{MHz}$ ) showing proton signals for photoproducts 1-3. Signal from the dimer impurity is due to the high concentrations of fludioxonil used in the experiment. 


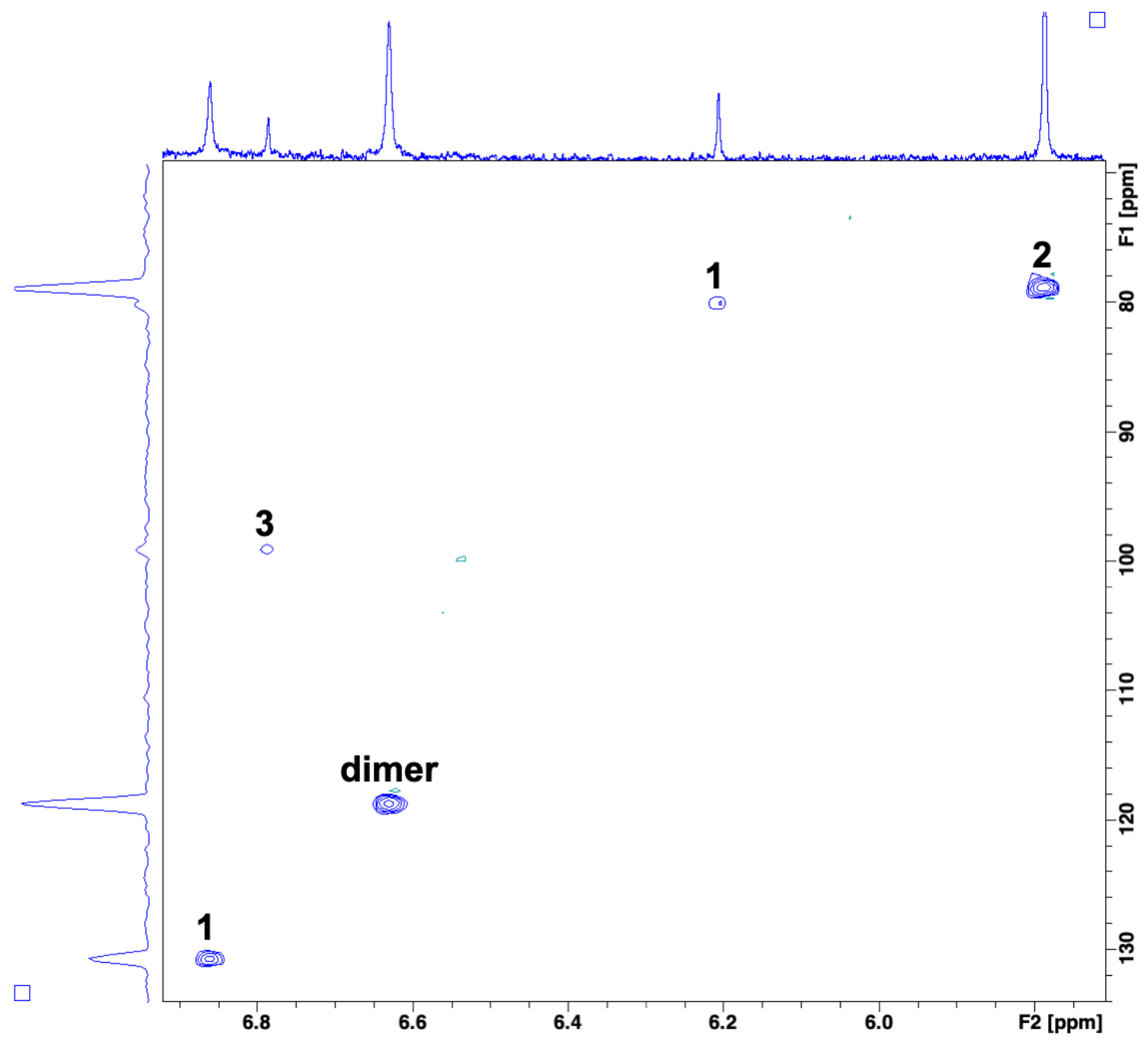

Figure S32. HSQC spectrum of fludioxonil photolysis mixture in 50:50 $\mathrm{CD}_{3} \mathrm{CN}: \mathrm{D}_{2} \mathrm{O}(400 \mathrm{MHz})$ showing $\mathrm{H} \rightarrow \mathrm{C}$ correlations for photoproducts 1-3 and dimer impurity. 


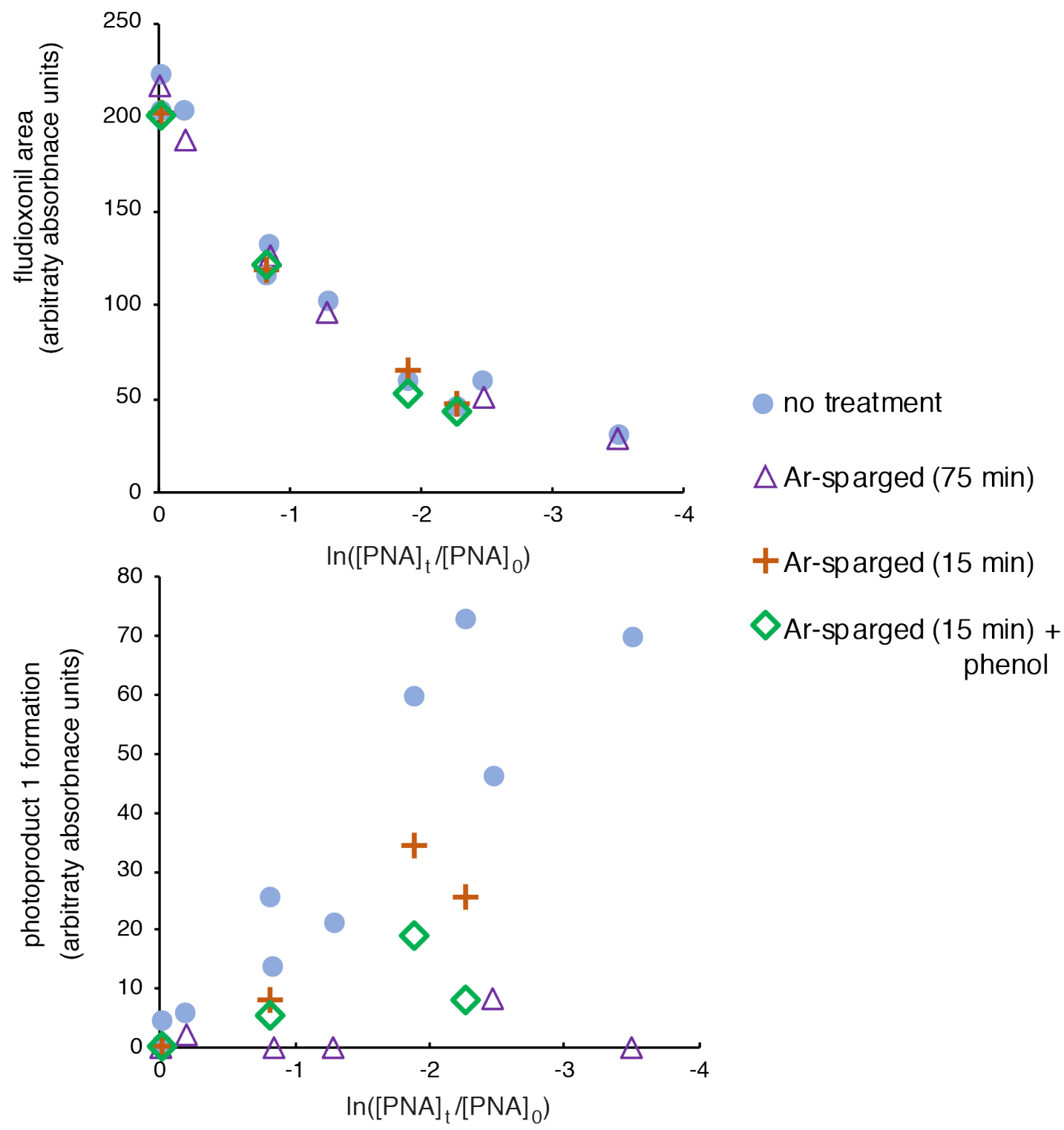

Figure S33. Direct photodegradation of fludioxonil (top panel) exposed to the xenon arc lamp in water with simultaneous experiments with argon-sparged solution to remove oxygen or argonsparged solutions with $50 \mu \mathrm{M}$ phenol to potentially repair the radical formation along with the formation of photoproduct 1 (bottom panel) in these solutions. 


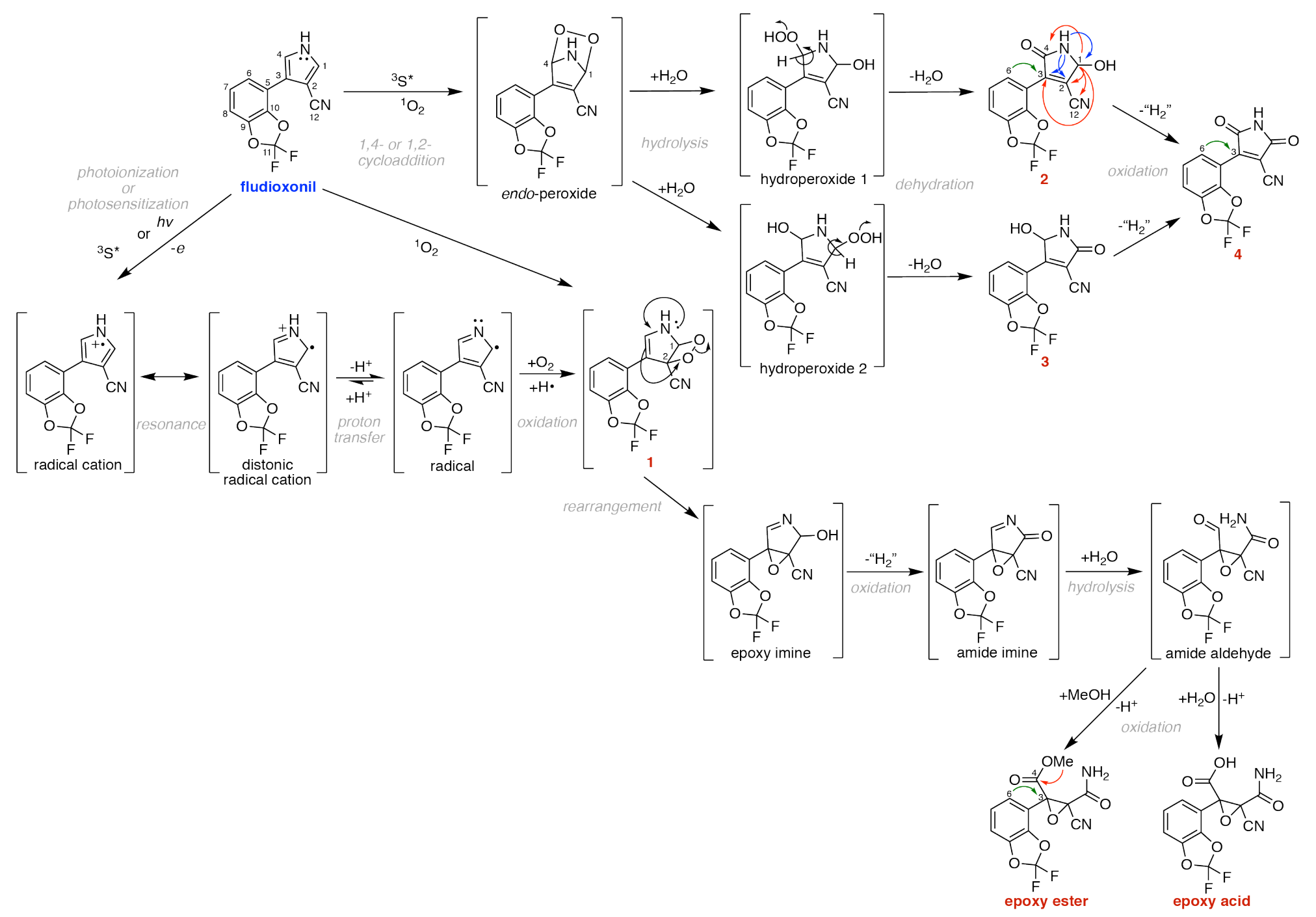

Figure S34. Proposed pathway for both direct and indirect photodegradation including the proposed pathway of photoproduct 1 in water to yield an epoxy acid product and in methanol to yield an epoxy ester. Key HMBC correlations for the isolated epoxy ester are represented by colored arrows. An analogous set of reactions could also occur from the 3,4-dioxetane regioisomer of $\mathbf{1}$. 


\section{Degradation of Photoproduct 1}

Storage of a fludioxonil photolysis mixture in 50:50 ACN: $\mathrm{H}_{2} \mathrm{O}$ in the dark over a period of $\approx 6$ weeks showed the decomposition of 1 coinciding with the formation of a proposed ring-opened epoxy acid product [calculated $m / z: 311.0116(\mathrm{M}-\mathrm{H})^{-}$, experimental $\mathrm{m} / \mathrm{z}: 311.0108(\mathrm{M}-\mathrm{H})^{-}$, $267.0210\left(\right.$ loss of $\left.\mathrm{CO}_{2}\right)$ ].

An analogous product $\left[\mathrm{m} / \mathrm{z}: 325(\mathrm{M}-\mathrm{H})^{-}\right]$was isolated from a fludioxonil photolysis mixture stored in methanol, which was observed to form over a period of a few days coinciding with the decomposition of 1. ${ }^{1} \mathrm{H}$ NMR analysis of the isolated product showed the loss of the pyrrole proton signals and emergence of a deshielded three-proton singlet at $\delta 4.00(\mathrm{MeO}-)$ and two broad one-proton singlets at $\delta 6.33(\mathrm{~N}-\mathrm{H})$ and $\delta 5.58(\mathrm{~N}-\mathrm{H})$. The HMBC spectrum showed a key correlation (red arrow) from MeO- to an ester carbon at $\delta 160.6$ (C-4). The NMR shift data for aromatic $\mathrm{H} / \mathrm{C}-6, \mathrm{H} / \mathrm{C}-7$, and $\mathrm{H} / \mathrm{C}-8$ indicated that the 2,2-difluoro-1,3-benzodioxole unit matched that of the parent compound fludioxonil. Finally, H-6 showed a key correlation (green arrow) to an oxygenated carbon at $\delta 66.3$ (C-3), which allowed for the proposed structural assignment of the epoxy ester (Figure S34).

Dioxetane product 1 is proposed to decompose via rearrangement to form an epoxy imine intermediate. Oxidation of the epoxy imine by deprotonation and loss of " $\mathrm{H}_{2}$ " would yield an amide imine intermediate, which would be susceptible to hydrolysis to give an amide aldehyde (possibly responsible for the DNPH adduct in Figure S30). Oxidation of the amide aldehyde via hydrolysis or methanolysis and loss of a proton would yield the epoxy acid or epoxy ester products, respectively. An analogous set of reactions could also occur from the 3,4-dioxetane regioisomer of $\mathbf{1}$

\section{Laser Flash Photolysis Experiments} laser flash photolysis - direct ionization $300 \mathrm{~nm}$
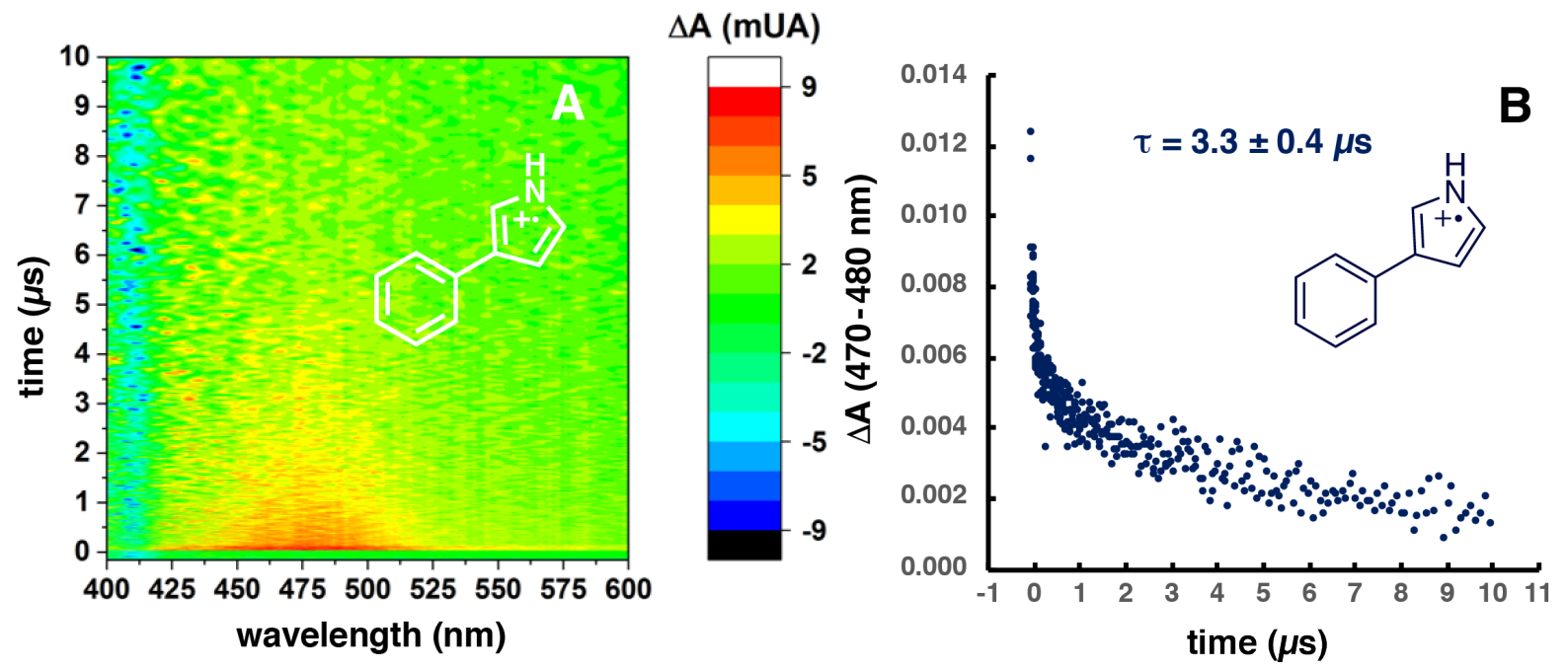

Figure S35. Laser flash photolysis of 3-phenylpyrrole with direct ionization. Panel A shows the transient absorption spectrum of the expected radical cation. Panel B shows the kinetic trace of this signal, which was fit with a biexponential decay equation to estimate the lifetimes of the singlet excited state $(88 \pm 9 \mathrm{~ns})$ and radical cation $(3.3 \pm 0.4 \mu \mathrm{s})$. 


\section{MAP sensitized $310 \mathrm{~nm}$}
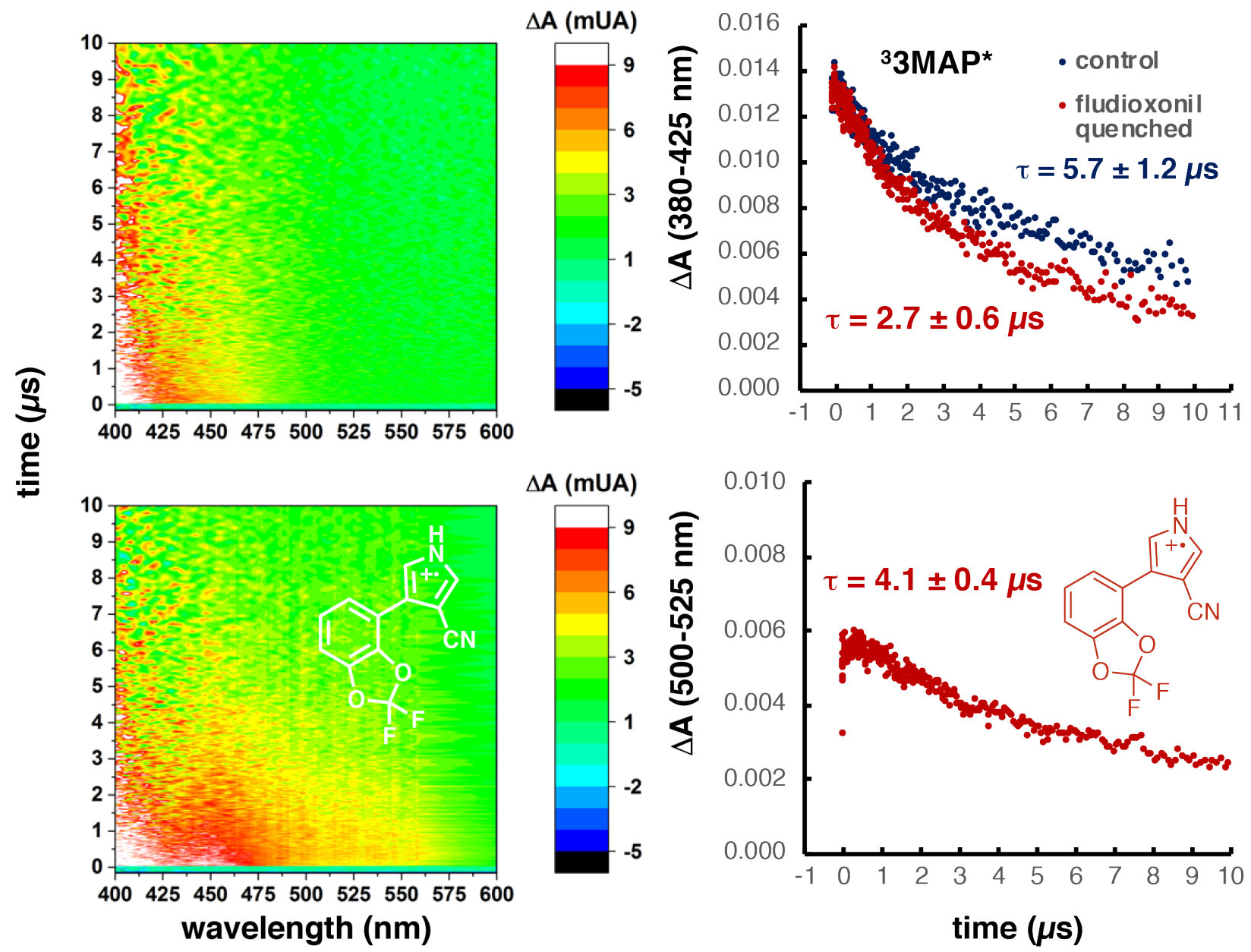

Figure S36. Laser flash photolysis of fludioxonil sensitized with 3MAP. The top row shows the signal for ${ }^{3} 3 \mathrm{MAP}^{*}$ (left) and the kinetic trace for ${ }^{3} 3 \mathrm{MAP} *$ with and without the addition of fludioxonil (right) in which fludioxonil is shown to quench the triplet signal (i.e., reducing the lifetime from 5.7 to $2.7 \mu \mathrm{s}$ ). The bottom row shows the signal for fludioxonil with $400 \mu \mathrm{M}$ of 3MAP present (left) and the kinetic trace (right) which shows the radical cation signal growing in and exhibiting the same lifetime as for direct ionization $(4.1 \mu \mathrm{s})$. 


\section{Reported Photoproducts}

aqueous photodegradation<smiles>N#CC1(C(N)=O)OC1(C(N)=O)c1cccc2c1OC(F)(F)O2</smiles>

CGA 339833

3-carbamoyl-2-cyano-3-(2,2difluorobenzo[d][1,3]dioxol-4yl)oxirane-2-carboxylic acid Chemical Formula: $\mathrm{C}_{12} \mathrm{H}_{6} \mathrm{~F}_{2} \mathrm{~N}_{2} \mathrm{O}_{6}$ Exact Mass: 312.02<smiles>N#CC(C(=O)O)C(C(N)=O)c1cccc2c1OC(F)(F)O2</smiles>

CGA 344623

2-cyano-3-(2,2-difluorobenzo[1,3]dioxol-4-yl)-succinamic acid

Chemical Formula: $\mathrm{C}_{12} \mathrm{H}_{8} \mathrm{~F}_{2} \mathrm{~N}_{2} \mathrm{O}_{5}$ Exact Mass: 298.04<smiles>N#CC(Cc1cccc2c1OC(F)(F)O2)C(=O)O</smiles>

A5

2-cyano-3-(2,2-difluorobenzo[d] $[1,3]$ dioxol-4-yl)propanoic acid Chemical Formula: $\mathrm{C}_{11} \mathrm{H}_{7} \mathrm{~F}_{2} \mathrm{NO}_{4}$ Exact Mass: 255.03

photodegradation in the presence of sediments/soils<smiles>O=C(O)c1cccc2c1OC(F)(F)O2</smiles>

CGA 192155 2,2-difluorobenzo[d] $[1,3]$ dioxole-4-carboxylic acid Chemical Formula: $\mathrm{C}_{8} \mathrm{H}_{4} \mathrm{~F}_{2} \mathrm{O}_{4}$ Exact Mass: 202.01<smiles>N#CC1=C(c2cccc3c2OC(F)(F)O3)C(=O)NC1=O</smiles>

\section{CGA 265378}

4-(2,2-difluoro-benzo[1,3]dioxol-4-yl)-2,5dioxo-2,5-dihydro-1 $\mathrm{H}$-pyrrole-3-carbonitrile

Chemical Formula: $\mathrm{C}_{12} \mathrm{H}_{4} \mathrm{~F}_{2} \mathrm{~N}_{2} \mathrm{O}_{4}$ Exact Mass: 278.01

Figure S37. Structures of photoproducts reported for photodegradation from the EFSA and FAO documentation. 
NMR Assignments and Degradation Kinetics for Pyrroles

Table S5. ${ }^{1} \mathrm{H}$ NMR assignments for three pyrrole compounds in $\mathrm{CDCl}_{3}$. Numbering follows the same as assigned for fludioxonil.

\begin{tabular}{cccc|} 
& pyrrole & 3-cyanopyrrole & 3-phenylpyrrole \\
proton & $\delta_{\mathrm{H}}$ mult. $(\mathrm{J}$ in $\mathrm{Hz})$ & $\delta_{\mathrm{H}}$ mult. $(\mathrm{J}$ in $\mathrm{Hz})$ & $\delta_{\mathrm{H}}$ mult. $(\mathrm{J}$ in $\mathrm{Hz})$ \\
\hline 1 & $6.87, \mathrm{dd}(4.4,2.2)$ & $7.31, \mathrm{dt}(3.1,1.6)$ & $7.10, \mathrm{dt}(2.6,1.8)$ \\
2 & $6.36, \mathrm{dd}(4.3,2.2)$ & & $6.56, \mathrm{td}(2.6,1.7)$ \\
3 & $6.36, \mathrm{dd}(4.3,2.2)$ & $6.49, \mathrm{td}(2.7,2.1)$ & \\
4 & $6.87, \mathrm{dd}(4.4,2.2)$ & $6.81, \mathrm{td}(2.7,1.4)$ & $6.85, \mathrm{td}(2.7,2.1)$ \\
6 & & & $7.54, \mathrm{~m}$ \\
7 & & & $7.34, \mathrm{~m}$ \\
8 & & & $7.18, \mathrm{~m}$ \\
9 & & & $7.34, \mathrm{~m}$ \\
10 & & & $7.54, \mathrm{~m}$ \\
$\mathrm{NH}$ & $8.22, \mathrm{br} \mathrm{m}$ & $8.87, \mathrm{brt}$ & $8.26, \mathrm{br}$ \\
\hline
\end{tabular}

Table S6. ${ }^{13} \mathrm{C}$ NMR assignments for three pyrrole compounds in deuterated chloroform. Numbering follows the same as assigned for fludioxonil.

\begin{tabular}{|cccc|} 
& pyrrole & 3-cyanopyrrole & 3-phenylpyrrole \\
carbon & $\delta_{\mathrm{c}}$ & $\delta_{\mathrm{c}}$ & $\delta_{\mathrm{c}}$ \\
\hline 1 & 117.8 & 125.8 & 114.5 \\
2 & 108.2 & 93.3 & 125.1 \\
3 & 108.2 & 111.9 & 106.6 \\
4 & 117.8 & 119.3 & 118.9 \\
5 & & & 135.8 \\
6 & & & 125.3 \\
7 & & & 128.6 \\
8 & & & 125.5 \\
9 & & & 128.6 \\
10 & & 117.0 & 125.3 \\
12 & & & \\
\hline
\end{tabular}


Table S7. HMCB correlations observed for three pyrrole compounds. Numbering follows the same as assigned for fludioxonil.

\begin{tabular}{|cccc|} 
proton & $\begin{array}{c}\text { pyrrole } \\
\mathrm{H} \rightarrow \mathrm{C \#}\end{array}$ & $\begin{array}{c}\text { 3-cyanopyrrole } \\
\mathrm{H} \rightarrow \mathrm{C} \#\end{array}$ & $\begin{array}{c}\text { 3-phenylpyrrole } \\
\mathrm{H} \rightarrow \mathrm{CH}\end{array}$ \\
\hline 1 & $2,3,4$ & $2,3,4$ & $2,3,4$ \\
2 & $1,3,4$ & & \\
3 & $1,2,4$ & 1,4 & $1,2,4$ \\
4 & $1,2,3$ & $1,2,3$ & $1,2,3$ \\
5 & & & 7,9 \\
6 & & & $2,8,10$ \\
7 & & & $5,6,8,9$ \\
8 & & & $6,7,9,10$ \\
9 & & & $5,7,8,10$ \\
10 & & & $2,6,8$ \\
12 & & no coupling & \\
$\mathrm{NH}$ & no coupling & no coupling & no coupling \\
\hline
\end{tabular}

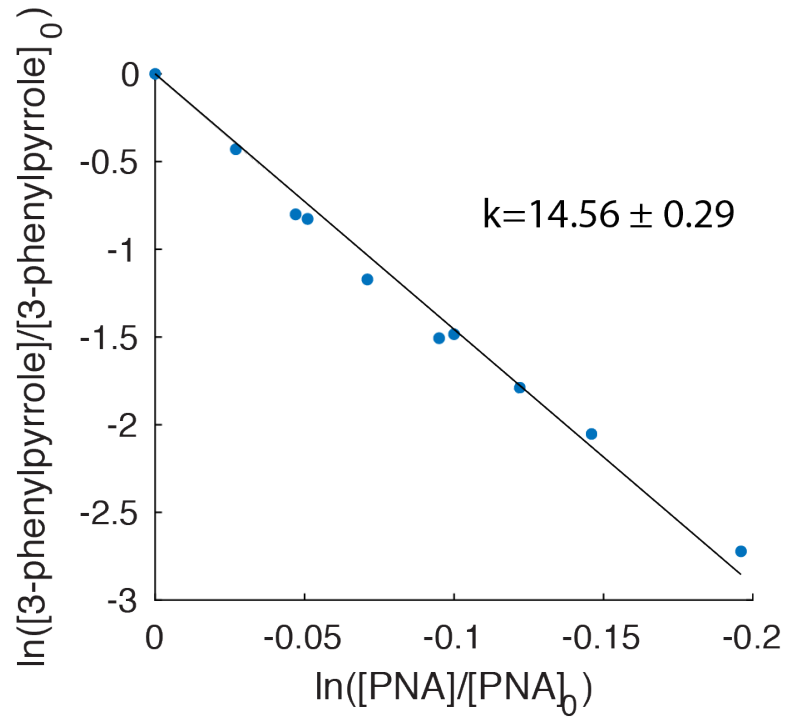

Figure S38. Direct photodegradation of 3-phenylpyrrole. Slope calculated from results from duplicate experiments ( $\mathrm{n}=9$ ), which was used to calculate the $\Phi=0.21$. 

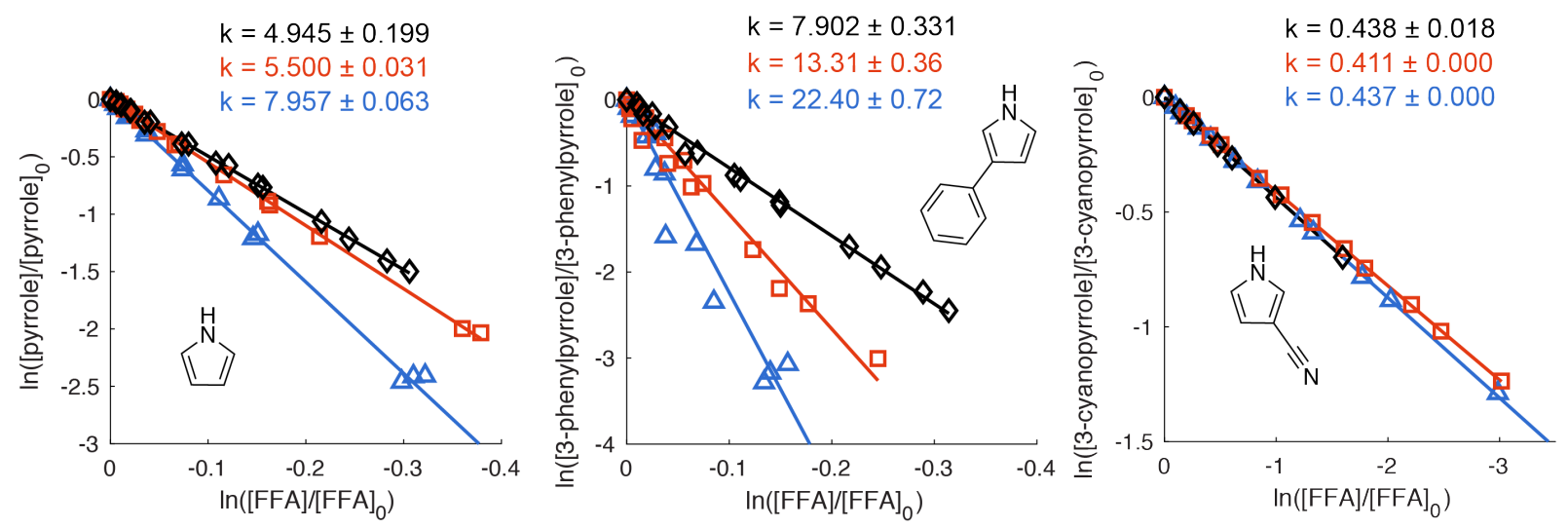

Figure S39. Degradation of pyrrole (left), 3-phenylpyrrole (middle), and 3-cyanopyrrole (right) plotted against FFA degradation. The values of the slopes $(\mathrm{k})$ are given above each graph for reactions with zinc porphyrin as the sensitizer (black), in water (blue), and in 80:20 $\mathrm{D}_{2} \mathrm{O}: \mathrm{H}_{2} \mathrm{O}$ (red). The bimolecular reactions rates with singlet oxygen can be calculated by multiplying the slopes from the zinc porphyrin experiments (top values in black) by the reaction rate constant for FFA $\left(1 \times 10^{8} \mathrm{M}^{-1} \mathrm{~s}^{-1}\right)$.

\section{Calculating Approximate Reaction Rate Constants with ${ }^{3} \mathbf{P N} *$}

If we assume $\left[{ }^{3} \mathrm{PN}^{*}\right]_{\mathrm{ss}}=\left[{ }^{1} \mathrm{O}_{2}\right]_{\mathrm{ss}}$ in the test solution, then we can use the ratio of observed degradation rates using $\mathrm{PN}$ (where reaction occurs with ${ }^{3} \mathrm{PN}^{*}$ and ${ }^{1} \mathrm{O}_{2}$ ) and $\mathrm{ZnP}$ (only reaction with ${ }^{1} \mathrm{O}_{2}$ ) as the photosensitizer to estimate an approximate reaction rate with ${ }^{3} \mathrm{PN}^{*}$ using the formula below:

$\frac{k_{F F A}^{P N}}{k_{F F A}^{Z n P}}=\frac{k^{3} P N^{*}\left[{ }^{3} P N^{*}\right]+k_{1} O_{2}\left[{ }^{1} O_{2}\right]}{k^{1} O_{2}\left[{ }^{1} O_{2}\right]}=\frac{k^{3} P N^{*}}{k^{1} O_{2}}+1$ 